\title{
Caracterização tectonoestrutural do Campo de Xaréu (Sub-Bacia de Mundaú, Bacia do Ceará - NE do Brasil): abordagem multiescala e pluriferramental
}

\author{
Alex Francisco Antunes ${ }^{1}$ Emanuel Ferraz Jardim de $S^{\prime}{ }^{1}$, Romero Gomes da Silva Araújo ${ }^{2}$ \& \\ Francisco Fontes Lima Neto ${ }^{3}$
}

\begin{abstract}
Resumo O Campo de Xaréu, localizado na porção centro-meridional da Sub-Bacia de Mundaú (leste da Bacia do Ceará), é caracterizado por um arranjo de falhas de direção NW-SE que mergulham principalmente para NE. Estas falhas compõem um leque lístrico distensional enraizado ao longo de uma superfície de detachment que corresponde à falha de Mundaú, na borda SW da sub-bacia homônima. A unidade carbonática principal do campo, o Membro Trairí (Neo-Aptiano a Eoalbiano, da Formação Paracuru), detém o maior volume de petróleo na área, concentrado em acumulações estruturalmente controladas. A partir de estudos estruturais realizados em testemunhos de sondagem e em perfis de imagem do Membro Trairí, foram caracterizadas duas gerações de estruturas em escalas meso e microscópica: (i) as estruturas $\mathrm{D}_{1}$ apresentam, em parte, um típico caráter hidroplástico, caracterizado por cisalhamentos intra e interestratais e zonas de cisalhamento oblíquas ao acamamento, além de feições frágeis tardias; (ii) as estruturas $\mathrm{D}_{2}$ apresentam um caráter estritamente frágil, sendo tipificadas por falhas normais e slickenlines de argilominerais recristalizados. Embora as falhas presentes no campo de Xaréu (e, por conseguinte, na Sub-Bacia de Mundaú) sejam classicamente referidas como estruturas de rejeito essencialmente normal, a análise cinemática das estruturas $\mathrm{D}_{1}$ observadas nos testemunhos permite definir que tais estruturas apresentam, de fato, deslocamentos oblíquos com sentido principal de transporte tectônico para ENE. Estes movimentos oblíquos seriam a resposta à instalação de um contexto transtracional na Sub-Bacia de Mundaú, por sua vez reflexo da tectônica transcorrente/transformante de abertura da Margem Equatorial Atlântica.
\end{abstract}

Palavras-chave: reservatório fraturado, Cretáceo, interpretação sísmica, testemunhos, Margem Equatorial.

\begin{abstract}
Tectono-structural characterization of Xaréu Oil Field (Mundaú Sub-Basin, Ceará Basin - NE Brazil): a multi-scale and multi-tool approach. The Xaréu Oil Field, located in the centralsouthern portion of Mundaú Sub-Basin (eastern Ceará Basin), is characterized by an array of NW-trending and NE-dipping normal faults. Those faults constitute an extensional listric fan rooted along a detachment surface which corresponds to the Mundaú Fault, located at the southwestern border of Mundaú Sub-Basin. The main carbonatic unit in the oil field, the Trairí Member (Paracuru Formation, Early Aptian to Early Albian), contains the largest oil volume in the area, which is concentrated in structurally controlled accumulations. The structural analysis carried out by drill cores and image profiles studies of the Trairi Member identified two generations of meso- to microscale structures: (i) the earliest $\mathrm{D}_{1}$ structures partially present a typical hydroplastic character, characterized by bedding-parallel and oblique shear zones, besides late brittle structures; and (ii) the $\mathrm{D}_{2}$ structures present a typical brittle character, encompassing normal faults and recrystallized argillaceous slickenlines. Although the macrofaults observed in the Xaréu Oil Field (and, consequently, in the Mundaú Sub-Basin) are classically referred as dip-slip normal faults, the kinematic analysis of the $\mathrm{D}_{1}$ structures indicates that such faults are, actually, oblique-slip structures, presenting tectonic transport towards ENE. Those oblique movements might be the response to the onset of a transtractive context in the Mundaú Sub-Basin, which is, ultimately, the result of a strike-slip tectonics that took place during the origin of the Atlantic Equatorial Margin.
\end{abstract}

Keywords: fractured reservoir, Cretaceous, seismic interpretation, drill cores, Equatorial Margin.

INTRODUÇÃO O texto apresentado a seguir traz uma descrição das atividades e a interpretação dos resultados obtidos com a caracterização geológico-estrutural do Campo de Xaréu, localizado na porção centroocidental da Sub-Bacia de Mundaú (Bacia do Ceará,
Nordeste do Brasil). O objetivo central da pesquisa foi o aperfeiçoamento de um método de caracterização da trama de fraturamento natural em reservatórios nãoaflorantes e a determinação da influência que esta trama exerce sobre o acúmulo, selo e fluxo de óleo no reser-

1 - Departamento de Geologia e Programa de Pós-Graduação em Geodinâmica e Geofísica/PRH-22, Universidade Federal do Rio Grande do Norte. Natal (RN), Brasil. E-mail: alex@geologia.ufrn.br

2 - PETROBRAS, UN-RNCE, Natal (RN), Brasil.

3 - PETROBRAS, CENPES. Cidade Universitária, Rio de Janeiro (RJ), Brasil. 
vatório, aplicando conceitos de amostragem de falhas em várias escalas.

Uma vez bem caracterizados os campos de tensões que governaram a instalação da Sub-Bacia de Mundaú durante o Aptiano, e a origem e migração de óleo, que pode ter finalizado no Neógeno (Costa et al. 1989), o estudo visou à aplicação deste conhecimento à viabilização de perfurações de poços multilaterais no Campo de Xaréu, cujo objetivo final foi o aumento do fator de recuperação de óleo de seu reservatório mais importante, o Membro (Calcário) Trairí.

O Calcário Trairí da Formação Paracuru detém quase metade do volume de petróleo original do Campo de Xaréu, que está concentrado em acumulações estruturalmente controladas (Ribeiro et al. 1986, Farias et al. 1998, Antunes et al. 2001, 2002, 2003, Antunes 2004). Todavia, uma vez que a distribuição da trama de fraturamento natural no reservatório é pouco conhecida, o fator de recuperação de óleo neste sistema é muito baixo (cerca de 5\%). Assim, a abordagem proposta procurou suprir parte das restrições observadas nas interpretações disponíveis, complementando com novos dados o quadro estrutural do Campo de Xaréu, com aplicação de métodos modernos de caracterização de reservatórios petrolíferos fraturados. O estudo estrutural detalhado foi de suma importância para a determinação da distribuição, orientação e densidade das fraturas e sua influência na permoporosidade do reservatório, o que, por seu turno, são informações cruciais na definição de estratégias de perfuração, principalmente no caso de poços direcionais e/ou multilaterais.

Finalmente, deve-se registrar que as atividades desenvolvidas tiveram o suporte financeiro do projeto "Caracterização Geomecânica de Reservatórios Heterogêneos para Aumento do Fator de Recuperação através da Perfuração de Poços Multilaterais" (FINEP/ CT-PETRO/PETROBRAS) e importante apoio logístico (incluindo a cessão de dados) da PETROBRAS UNRNCE.

MATERIAIS E MÉTODOS DE TRABALHO A caracterização geológica e estrutural foi realizada por meio de diversas técnicas, em diferentes escalas de abordagem. Ao todo, foram interpretados e/ou analisados 16 seções sísmicas migradas em tempo, 36 testemunhos de sondagem (perfazendo $356,3 \mathrm{~m}$ ), 3 suítes de perfis de imagens e cerca de 100 seções delgadas dos testemunhos.

Todos os dados utilizados foram cedidos pela PETROBRAS. A descrição dos testemunhos de sondagem foi realizada no Laboratório de Geologia da PETROBRAS (UN-RNCE). As seções sísmicas foram interpretadas em estações de trabalho do Laboratório de Interpretação Geofísica e Visualização do Programa de Pós-Graduação em Geodinâmica e Geofísica da Universidade Federal do Rio Grande do Norte, empregando-se o programa SeisX, versão 3.6.2 para plataforma Microsoft Windows, desenvolvido pela Paradigm Geophysical Company.

\section{SINOPSE DA GEOLOGIA E A ESTRUTURACC̃O REGIONAL DA SUB-BACIA DE MUNDAÚ O}

Campo de Xaréu está localizado no setor oriental da Bacia do Ceará. Esta, por seu turno, corresponde a um segmento da Margem Equatorial Atlântica brasileira (Fig. 1a), cuja origem remonta aos eventos tectônicos que culminaram com a ruptura e fragmentação do supercontinente Gondwana durante o Cretáceo Inferior.

A Bacia do Ceará é bordejada a leste pela Bacia Potiguar, apresentando o alto de Fortaleza como feição limítrofe de ambas. A oeste, a Bacia do Ceará é separada de sua vizinha, a Bacia de Barreirinhas, por meio do alto de Tutóia. O substrato da bacia é composto por rochas cristalinas pré-cambrianas da porção noroeste da Província Borborema, entrecortadas por zonas de cisalhamento cujo último pulso de atividade dúctil ocorreu durante a Orogênese Brasiliana, ao final do Neoproterozóico. Tais estruturas apresentaram papel crucial na evolução da Bacia do Ceará, uma vez que parte delas foi reativada durante o Cretáceo, atuando como controladoras do aparecimento de algumas das falhas principais e pela segmentação da Bacia do Ceará. Graças a esta segmentação, a Bacia do Ceará pode ser dividida em compartimentos (ou sub-bacias) com características estruturais distintas. Assim, de oeste para leste são reconhecidas as sub-bacias de Piauí-Camocim, Acaraú, Icaraí e Mundaú (Fig. 1b), esta última que aloja a área foco das pesquisas apresentadas neste trabalho.

A Sub-Bacia de Mundaú está localizada na porção leste da Bacia do Ceará (Fig. 1b), sendo bordejada a oeste pela falha de Forquilha, limite com a Sub-Bacia de Icaraí, e a leste pelo alto de Fortaleza, que separa a Sub-Bacia (e, por conseqüência, a Bacia do Ceará) da Bacia Potiguar (Fig. 2a). Falhas normais de direção NW-SE com mergulhos para NE são as principais estruturas encontradas nesta sub-bacia, destacando-se a falha de Mundaú, que separa as seções sinrifte (Formação Mundaú) e tardirrifte (Formação Paracuru), dispostas a nordeste da falha, da plataforma de Fortaleza, localizada a sudeste. Falhas de direção NE-SW, possivelmente representando estruturas de transferência, associam-se às falhas principais, segmentando a Sub-Bacia de Mundaú em blocos menores.

A Sub-Bacia de Mundaú ocupa uma posição peculiar na Margem Equatorial Atlântica brasileira, localizando-se ao longo de um setor que experimentou deformações transtrativas condicionadas pela tectônica transcorrente/transformante ao longo da margem (Matos et al. 1996). Neste contexto, a Sub-Bacia de Mundaú estaria alojada em uma estrutura análoga a uma bacia pull-apart. Ainda que a orientação das falhas principais seja bem conhecida, o verdadeiro sentido de transporte tectônico a elas relacionado ainda é objeto de discussão: se for considerado que a bacia foi originada segundo um rifteamento ortogonal, o transporte tectônico teria sentido NE; por outro lado, caso seja assumida uma abertura por rifteamento oblíquo, associado aos movimentos transcorrentes/transformantes dextrais, seria esperado que as falhas normais apresentassem rejeitos também oblíquos (normal + direcional dextral 
(a)
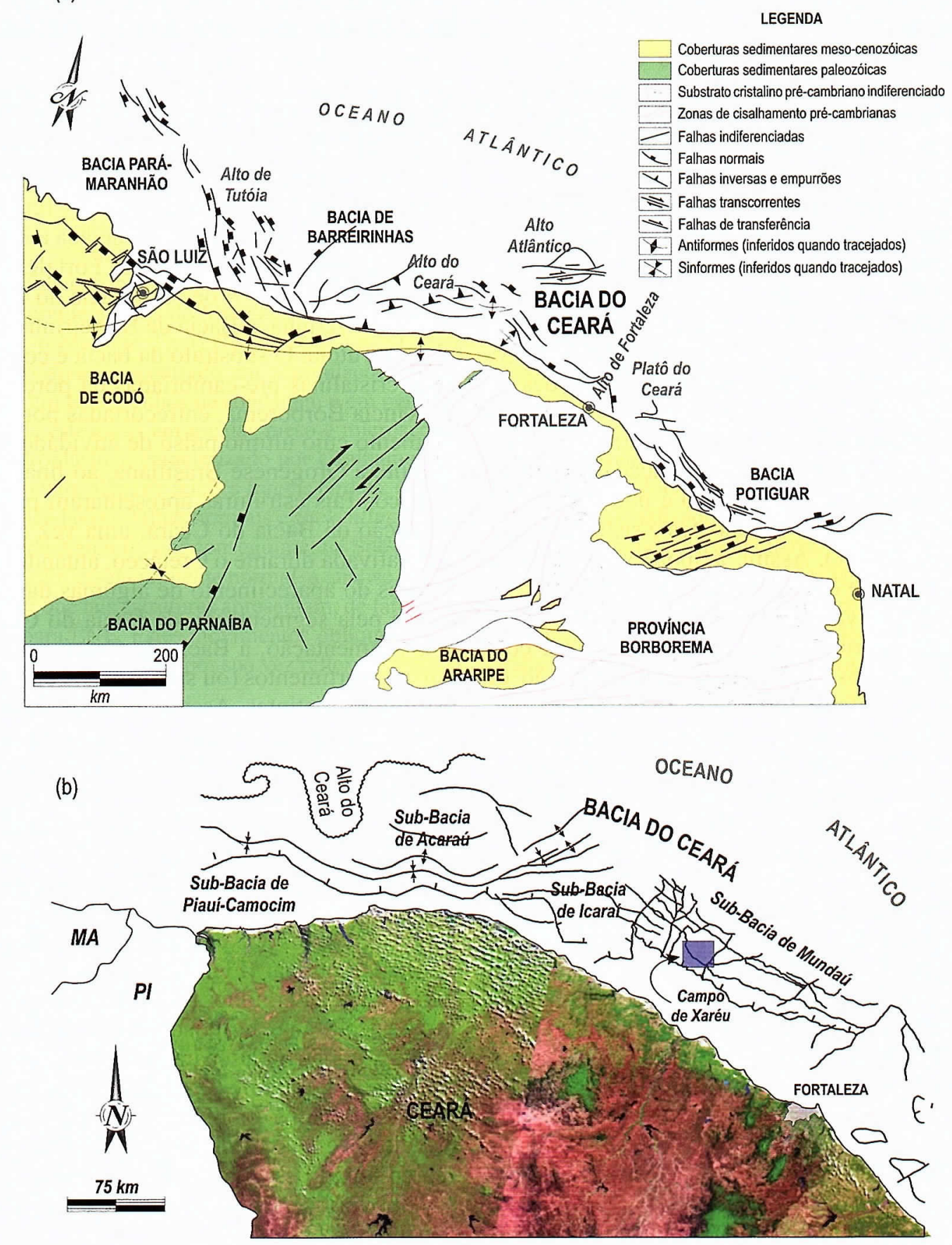

Figura 1 - Localização e contexto tectonoestrutural da Bacia do Ceará. (a) Mapa tectonoestrutural de parte do Nordeste brasileiro com a localização da Margem Equatorial Atlântica brasileira e a Bacia do Ceará (modificado de Davison 1998); (b) arcabouço estrutural da Bacia do Ceará, incluindo suas sub-bacias, dentre as quais se encontra a Sub-Bacia de Mundaú.

subordinado), com transporte tectônico dominante para ENE.

Localizado na porção centro-ocidental da SubBacia de Mundaú, o Campo de Xaréu está alojado ao longo de um segmento de uma das falhas NW-SE sintéticas em relação à falha de Mundaú (Fig. 2). O preenchimento sedimentar do campo é dado por depósitos sedimentares continentais relacionados à fase de sinrif- te da Sub-Bacia de Mundaú, agrupados na Formação Mundaú (Eo a Mesoaptiano - Fig. 3). Uma seqüência tardirrifte depositada em ambientes continental a transicional, a Formação Paracuru (Mesoaptiano a Eoalbiano - Fig. 3), capeia a unidade precedente. Rochas carbonáticas albianas compõem a seção superior da Formação Paracuru, constituindo o Membro Trairí, que é o principal reservatório de hidrocarbonetos do Campo 
(a)
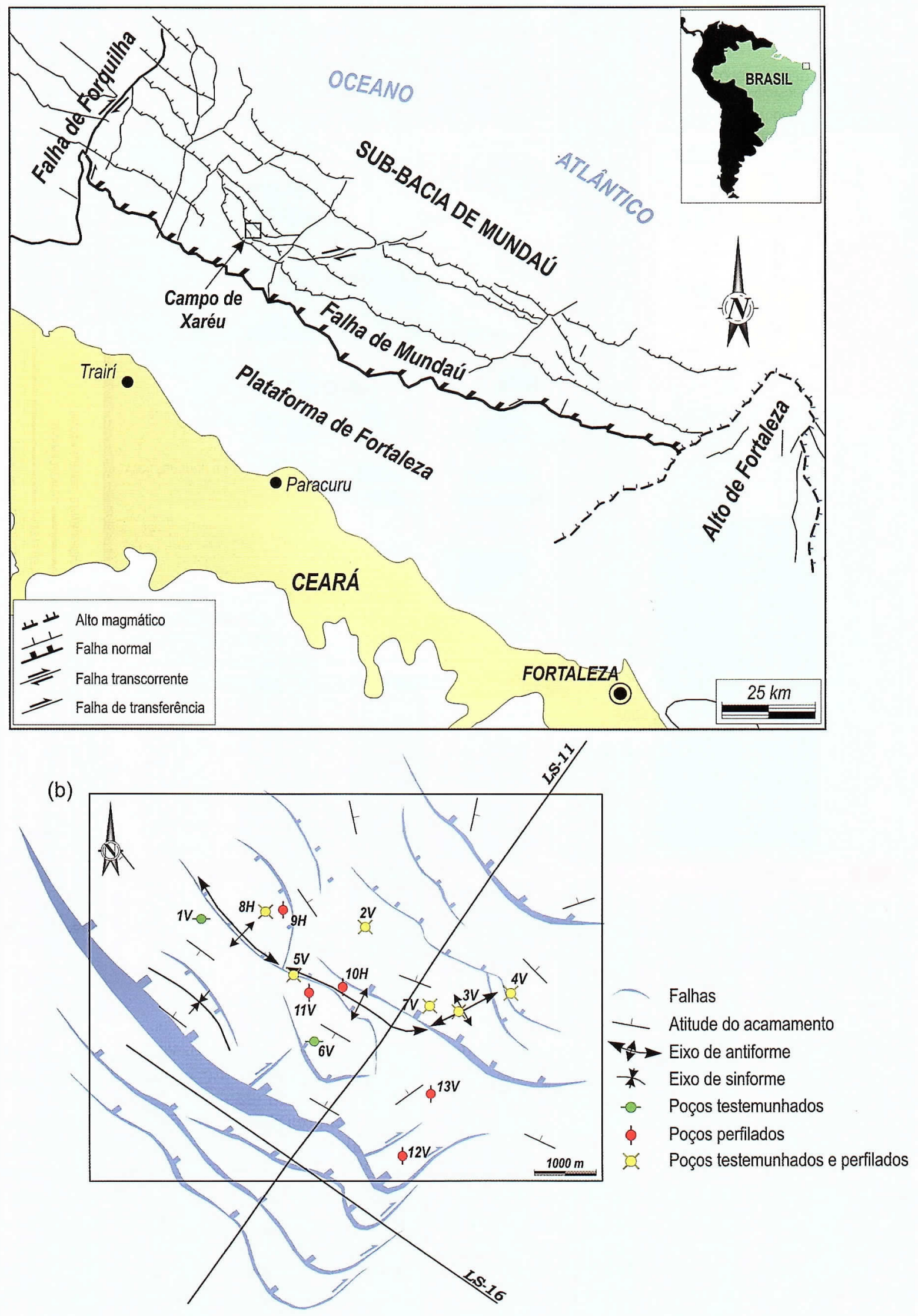

Figura 2 - Localização e contexto tectonoestrutural da Sub-Bacia de Mundaú e do Campo de Xaréu. (a) Mapa estrutural simplificado da Sub-Bacia de Mundaú. Modificado de Matos et al. (1996) e PETROBRAS (1996); (b) mapa estrutural simplificado do Campo de Xaréu exibindo a localização dos poços e das seções sísmicas ilustradas no texto. Os sufixos $V$ e $H$ são empregados para definir poços verticais e horizontais, respectivamente. 


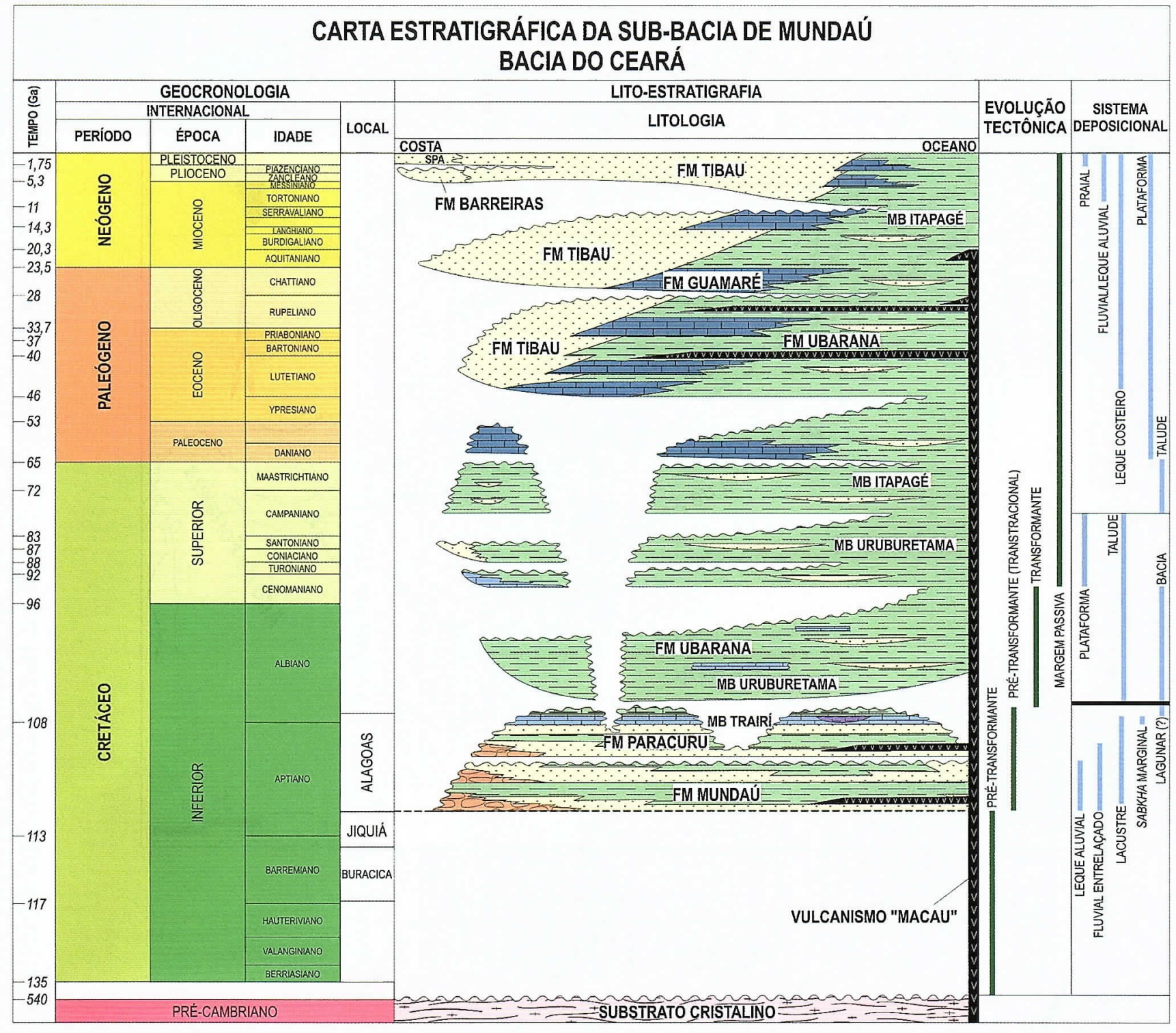

Figura 3 - Carta litoestratigráfica da Sub-Bacia de Mundaú (modificado de Beltrami et al. 1994). Os ambientes tectônicos e o intervalo de abrangência foram adaptados de Matos (2000).

de Xaréu. Finalmente, um espesso pacote relacionado à fase de deriva continental e implantação da margem passiva a partir do Eoalbiano e que engloba as formações Ubarana, Guamaré e Tibau (Fig. 3), completa a unidades presentes no campo.

ARCABOUÇO ESTRUTURAL DO CAMPO DE XARÉU A arquitetura da Sub-Bacia de Mundaú é regionalmente estruturada por uma falha principal, a falha de Mundaú, que possui um importante rejeito normal com direção NW-SE e mergulho para NE (Fig. 2a). No Campo de Xaréu, a falha de Mundaú é caracterizada por uma geometria que varia de rampa-patamar-rampa a lístrica, enraizada em uma superfície de descolamento basal, do qual todo o feixe lístrico distensional de Campo de Xaréu se estrutura (Fig. 4). Próximo ao alto de Fortaleza (Fig. 2a), a falha de Mundaú apresenta perfil que varia entre plana, sigmoidal e em rampa-patamar- rampa (Matos et al. 1996), variação esta que define setores de comportamento estrutural distinto em toda a Sub-Bacia de Mundaú.

Na área do Campo de Xaréu ocorre um arranjo principal de falhas normais sintéticas à falha de Mundaú (Fig. 2b) e que se dispõem segundo um leque lístrico distensional. O campo é delimitado a sul pela falha de Xaréu, que afeta principalmente as formações Mundaú e Paracuru, e o Membro Trairí. Falhas sintéticas de pequeno porte, limitadas à Formação Mundaú, enraízamse na falha de Xaréu, apresentando perfil relativamente retilíneo.

Falhas normais antitéticas ocorrem principalmente na porção oeste do Campo de Xaréu, apresentando, em geral, geometria lístrica pouco desenvolvida e mergulhos mais elevados que as principais falhas do campo. As falhas antitéticas poderiam ter se desenvolvido com mergulhos originalmente mais suaves, ten- 


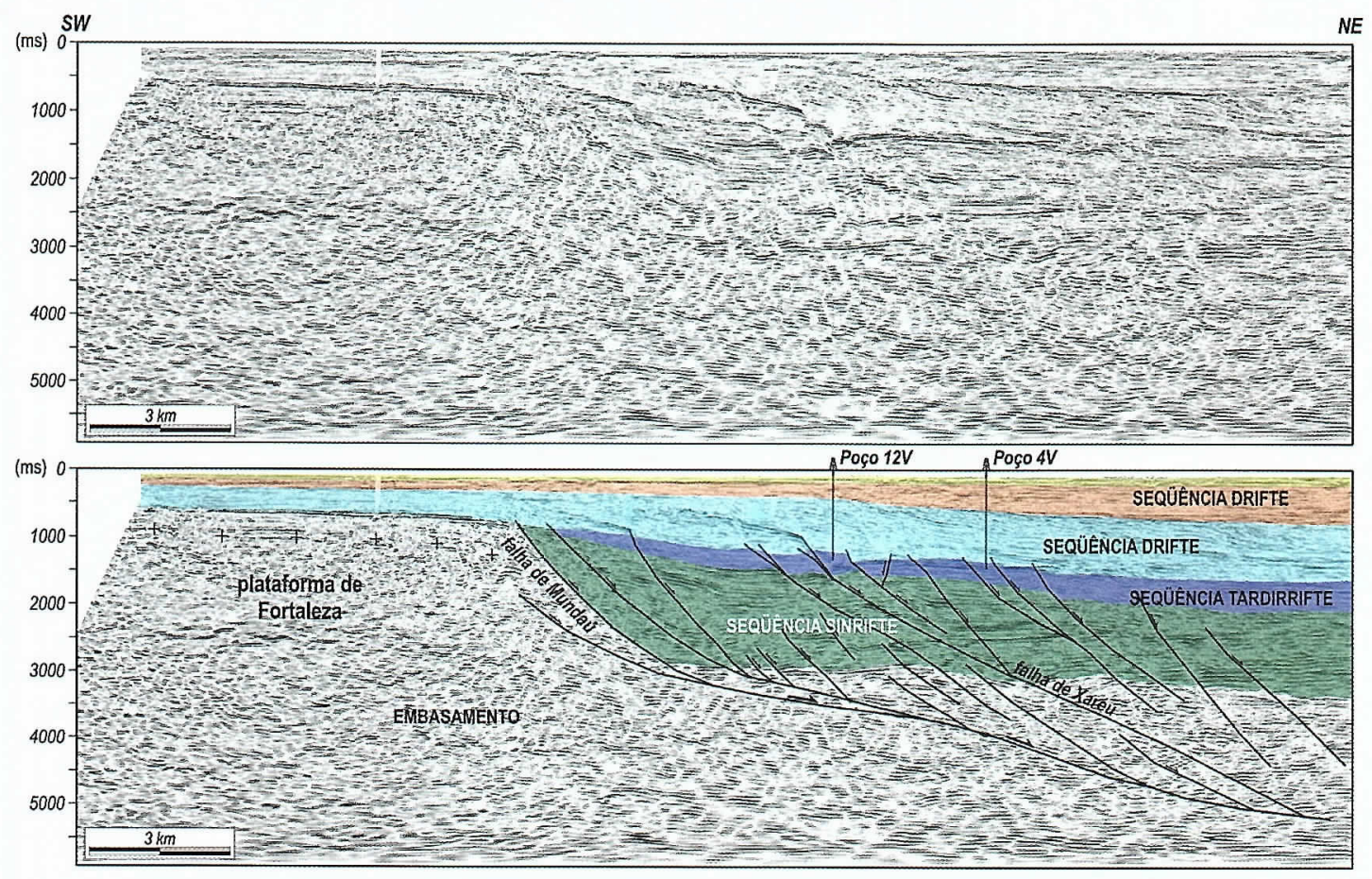

\begin{abstract}
Figura 4 - Seção sísmica LS-11 (localização na Fig. 2), transversal à estruturação principal do Campo de Xaréu, exibindo a geometria em rampa-patamar-rampa da Falha de Mundaú e do leque lístrico distensional que tipifica o campo.
\end{abstract}

do sido progressivamente rotacionadas em função da evolução do dobramento distensional presente. Falhas de alto ângulo, de direção NE-SW e com sutil deslocamento vertical normal, relacionam-se às falhas lístricas, muito provavelmente atuando como falhas de transferência.

A sudeste do campo ocorrem falhas que se arranjam conforme uma geometria similar à observada em estruturas-em-flor negativas (Fig. 5). Estas falhas, que afetam principalmente o embasamento e as formações Mundaú e Paracuru, exibem altos mergulhos em profundidade, diminuindo de ângulo em direção à superfície, passando a mergulhar para SE ou para NW. Uma vez que esta estrutura foi identificada apenas em uma seção sísmica, não foi possível determinar sua direção, somente sendo possível inferi-la pela comparação com feições similares vizinhas e que apresentam direção NE-SW.

As geometrias em rampa-patamar-rampa e lístrica das falhas do campo, em particular da falha de Xaréu, provocaram o dobramento das camadas presentes no bloco do teto, imprimindo uma característica geometria em anticlinal rollover às unidades presentes. O dobramento exibe geometria suave, ligeiramente assimétrica (vergência para SW) e perfil paralelo. $\mathrm{O}$ eixo é curvilíneo e apresenta duplo caimento, denotando que o anticlinal rollover representa, na realidade, uma geometria dômica.

\section{A DEFORMAÇÃO EM MESOESCALA} Análise dos Testemunhos de Sondagem A caracterização estrutural dos testemunhos analisados permitiu a individualização de, pelo menos, duas gerações de estruturas tectônicas, que se distinguem pelo regime de deformação, cinemática, associação com fluidos e relações temporais com a deposição das rochas da Formação Paracuru.

\section{A REORIENTAÇÃO DOS TESTEMUNHOS Durante} o processo de testemunhagem convencional, a orientação original dos testemunhos coletados é perdida pelo fato de que os mesmos, uma vez que estejam destacados da formação, rotacionam em torno de seu eixo. Em certos casos, são utilizados equipamentos e peças especiais que propiciam a orientação do testemunho ainda durante a perfuração. Trata-se, entretanto, de uma técnica relativamente cara e, portanto, de emprego muito pouco difundido.

No caso em que os testemunhos estudados não sejam originalmente orientados, é preciso lançar mão de técnicas auxiliares para recuperar a orientação dos mesmos. Quaisquer que sejam os métodos e ferramentas empregados, para obter-se a atitude verdadeira de uma estrutura em um testemunho, como falhas e fraturas, é necessário conhecer a atitude real do acamamento no testemunho. Para a aplicação do método de reorientação dos testemunhos dos poços estudados foram utilizados essencialmente os dados de mapas e seções estruturais do Campo de Xaréu. O método consiste inicialmente na determinação do sentido de mergulho do acamamento nas proximidades do poço, obtida a partir da análise das curvas de contorno estrutural do mapa (Fig. 6). Em seguida, posiciona-se o testemunho analisado sobre uma rosa-dos-ventos que contenha a marcação do sentido de 

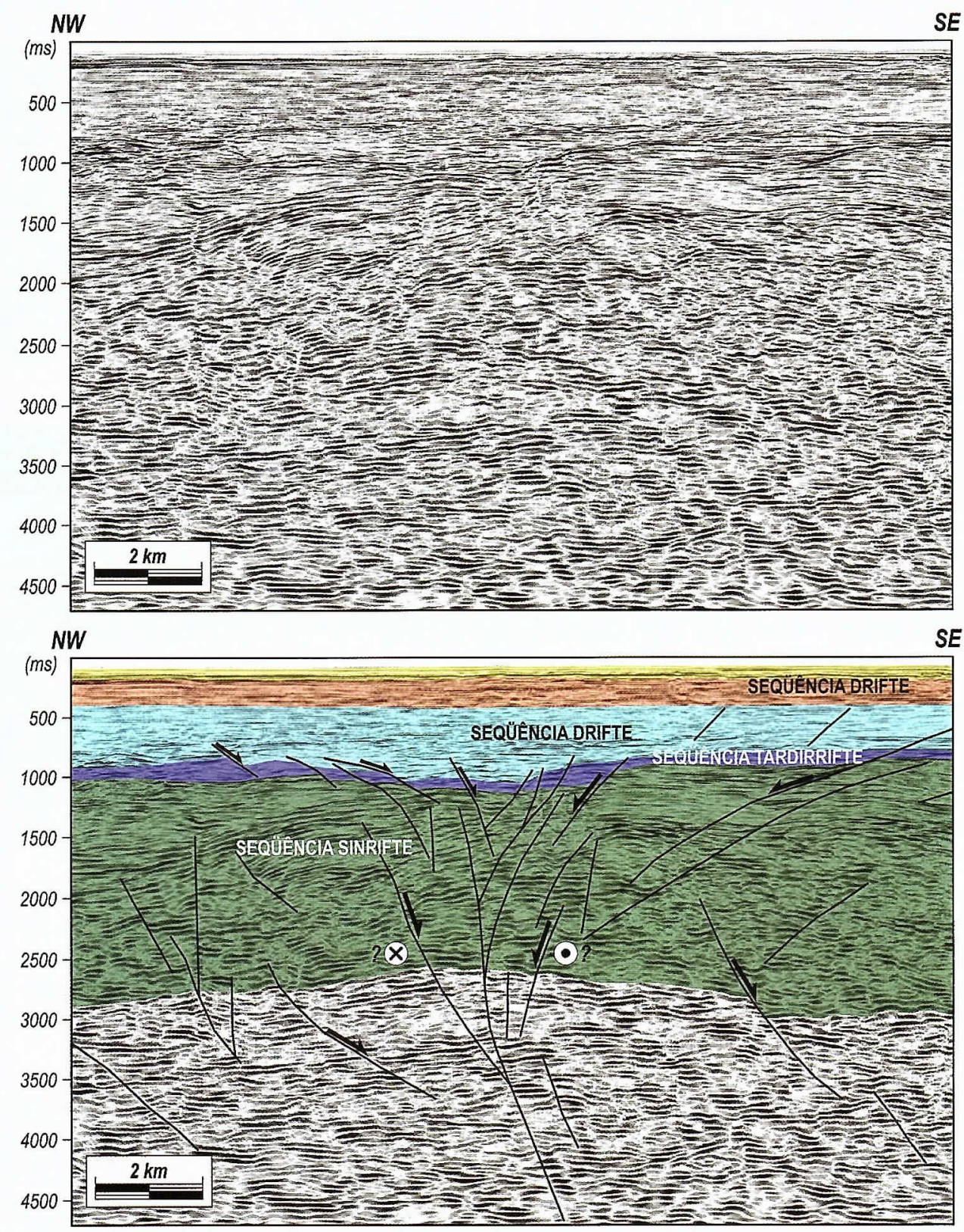

Figura 5 - Detalhe da seção sísmica longitudinal LS-16 (localização na Fig. 2) exibindo estrutura-em-flor negativa localizada a sudeste da área do Campo de Xaréu.

mergulho de $\mathrm{S}_{0}$ regional. O testemunho é rotacionado até que o sentido de mergulho das camadas observado nele coincida com regional (Fig. 6), medindo-se, então, a atitude da estrutura de interesse. A partir do conhecimento da atitude das camadas no testemunho, pode-se determinar a atitude das demais estruturas presentes.

Para a aplicação da técnica de reorientação é preciso que as camadas no testemunho não sejam horizontais, caso em que a solução seria indeterminada. Ademais, a aplicação do método requer que (i) os poços dos quais os testemunhos analisados foram extraídos devam ser perfeitamente verticais e que (ii) as hastes de perfuração sejam inflexíveis. Se uma destas premissas não for satisfeita, o testemunho apresentará camadas com mergulhos falsos. Se necessário, deve-se proceder a correção de mergulho do poço.

$S E$

$S E$

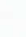

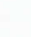



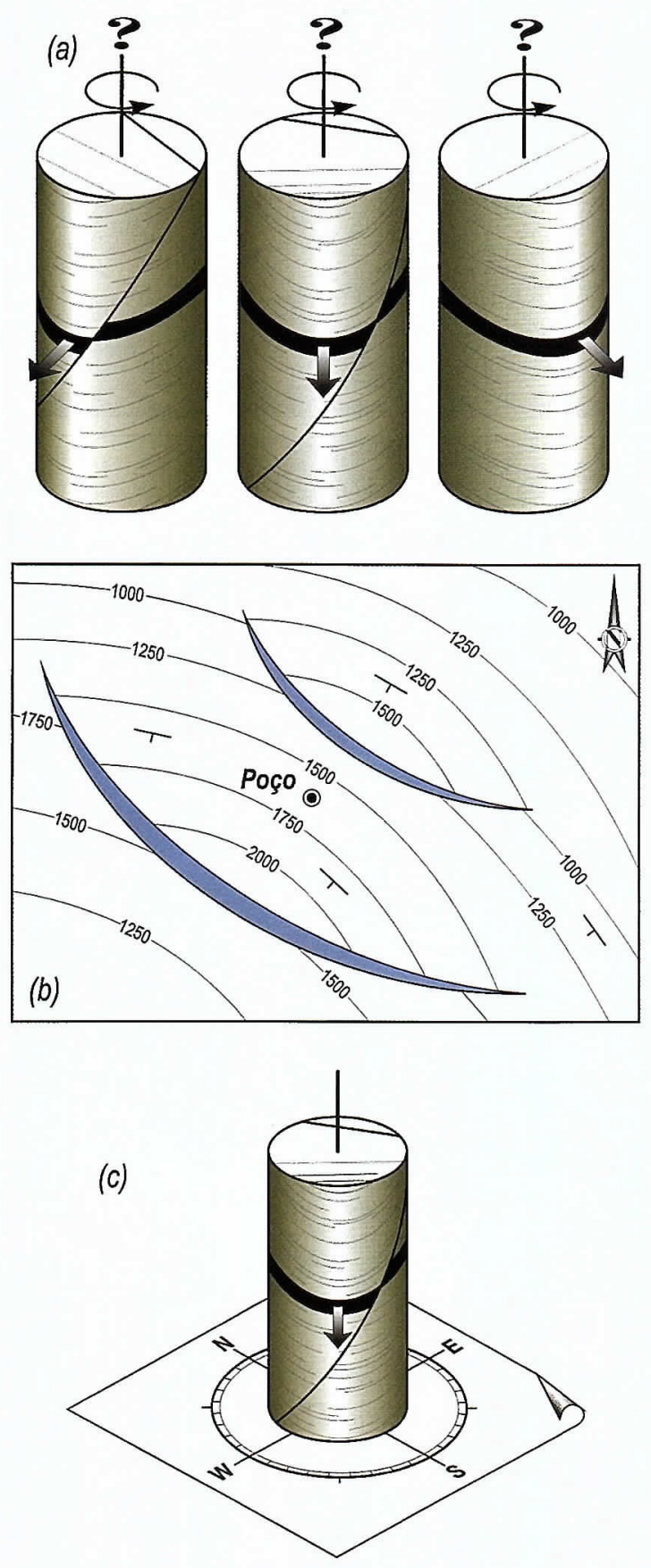

Figura 6 - Método de reorientação de testemunhos aplicado aos poços do Campo de Xaréu. $\mathrm{Na}$ maior parte dos casos, os testemunhos extraidos de campos de petróleo não são orientados, de forma que a atitude das estruturas neles presentes não pode ser recuperada (a). Conhecendo-se a localização exata do poço e o comportamento do acamamento (b), é possivel efetuar a reorientação de um segmento de testemunho, desde que $o$ acamamento apresente um mergulho mensurável. Lançando mão de uma rosa-dos-ventos, pode-se posicionar e girar o segmento do testemunho em questão, até que o mergulho do acamamento coincida com o sentido de mergulho das camadas determinadas a partir do mapa estrutural do campo petrolifero (c). por fim, um regime frágil. A passagem paulatina é o resultado direto do grau de litificação das rochas nas quais as estruturas foram desenvolvidas o que reflete $o$ teor de água presente no material sedimentar. Litologias pouco consolidadas e com elevada saturação de água favorecerão os estilos hidroplásticos, enquanto que em exemplos litificados, portanto com baixo teor em água, ocorrerão estilos mais frágeis.

O conjunto de estruturas mais precoce encontrado nos testemunhos de sondagem, $\mathrm{D}_{1}$, é representado por zonas de cisalhamento paralelas ao acamamento $\left(\mathrm{S}_{0}\right)$ das litologias afetadas (mais comumente folhelhos e calcilutitos laminados e acamadados do Membro Trairí), além de falhas normais oblíquas a $\mathrm{S}_{0}$, todas indicando o mesmo sentido de transporte tectônico. A característica que tipifica as estruturas $\mathrm{D}_{1}$ é o desenvolvimento de estilos morfologicamente semelhantes àqueles relacionados à deformação dúctil de alta temperatura. Deve-se salientar que, para enfatizar esta semelhança, os termos originalmente cunhados para tipificar as estruturas associadas à deformação dúctil serão tomados de empréstimo para definir as feições similares observadas nos testemunhos de sondagem estudados.

Normalmente os cisalhamentos (será aplicado o termo $\mathrm{C}_{1}$ para defini-los e $\mathrm{S}_{0}+\mathrm{C}_{1}$ para indicar a trama conjunta) não são muito bem desenvolvidos, sendo geralmente diagnosticados por meio de finas lineações no acamamento (análogas aos slickenlines fibrosos de falhas) e marcadores semicirculares deformados. Localmente cisalhamentos mais penetrativos imprimem forte deformação em marcadores semicirculares (clastos e intraclastos, nódulos e concreções de diversas naturezas, carapaças de ostrácodes), que podem se mostrar estirados, assumir formatos assimétricos (Fig. 7a) ou serem rotacionados (Fig. 7b,c), nestes dois últimos casos comportando-se como porfiroclastos $\sigma$ e $\delta$, respectivamente.

A trama composta $\mathrm{S}_{0}+\mathrm{C}_{1}$ apresenta mergulhos muito suaves (que poucas vezes excede os $10^{\circ}$ ), principalmente para SW e leste, com exemplos subordinados para NE, NNW e SSE, dependendo do poço analisado. As lineações $\left(L_{1}\right)$ presentes, por sua vez, apresentam direção principal ENE-WSW, com oscilações para NNESSW e NE-SW.

A deformação impressa pelos cisalhamentos $\mathrm{C}_{1}$ mais conspícuos também pode desenvolver tramas oblíquas, análogas às estruturas S-C (Fig. 8a) e S-C' (Fig. 8b), ambas mais bem desenvolvidas em margas e calcilutitos laminados. Eventualmente, os fragmentos de matéria orgânica podem posicionar-se obliquamente em relação à laminação sedimentar, funcionando como bons indicadores cinemáticos dos cisalhamentos $\mathrm{C}_{1}$ (Fig. 8c).

As estruturas $\mathrm{D}_{1}$ de caráter hidroplástico/frágil a frágil são mormente definidas por zonas de cisalhamento e falhas normais, com direção principal NW-SE e mergulhos tanto para NE como para SW (Fig. 9). Estruturas de direções NE-SW e N-S ocorrem de forma subordinada, também apresentando rejeitos normais (Fig. 9). 

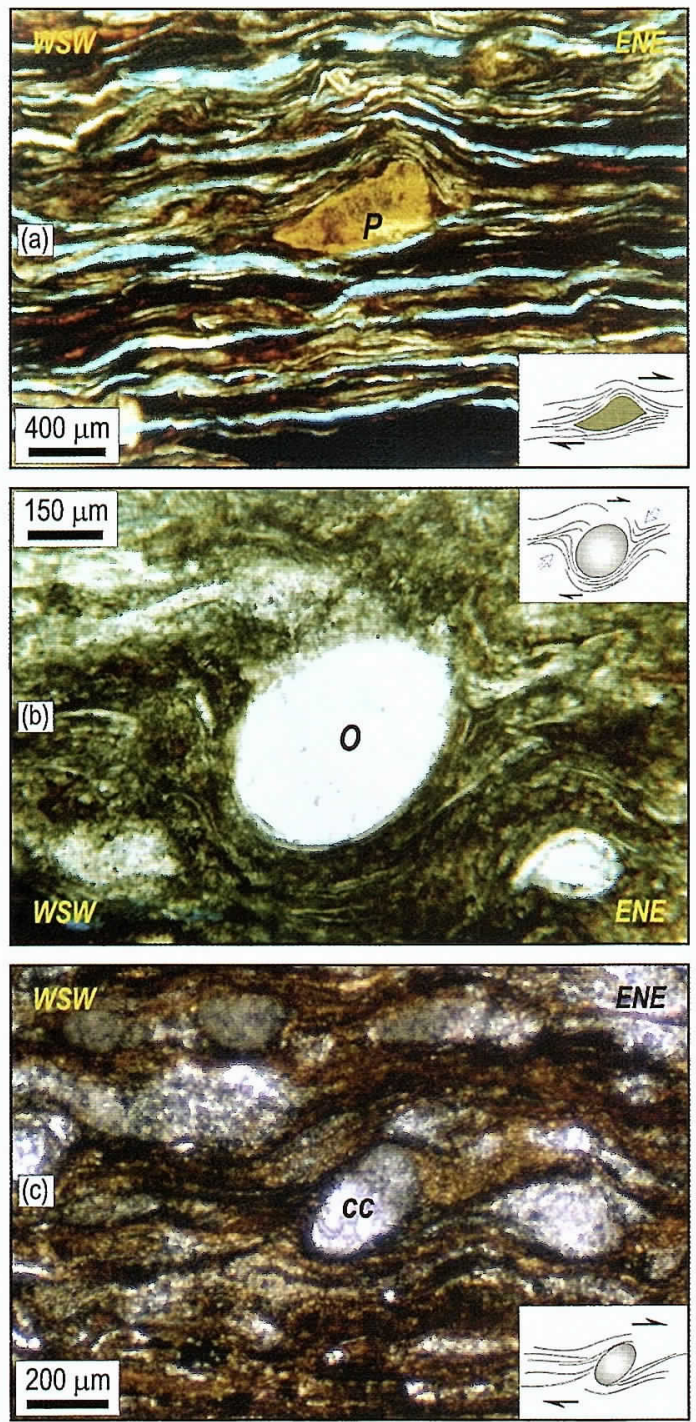

Figura 7 - Deformação $D$, afetando marcadores semicirculares. (a) Clasto fosfatizado " $P$ " sigmoidal na trama composta $S_{0}+C_{1}$ de uma marga, indicando sentido de transporte tectônico para ENE. Nicóis paralelos. Poço $6 \mathrm{~V}$; (b) ostrácode " $\mathrm{O}$ " rotacionado, configurando um clasto tipo $\delta$, imerso na laminação composta $S_{0}+C_{1}$ de uma marga, com indicação de sentido de transporte tectônico para ENE. Nicóis paralelos. Poço 5V; (c) clasto elíptico de calcita "cc" rotacionado, indicando sentido de transporte tectônico ENE em um calcilutito laminado. Nicóis cruzados. Poço 2V. Localização dos poços na figura 2.

A característica diagnóstica das zonas de cisalhamento é o estiramento e o desenvolvimento de dobras de arrasto em marcadores planares como a laminação (Fig. 10a) e/ou a trama composta $\mathrm{S}_{0}+\mathrm{C}_{1}$ e veios de calcita. "Peixes" formados por fragmentos de folhelho também denotam a "ductilidade" da deformação relacionada às zonas de cisalhamento.

Gradualmente, as zonas de cisalhamento dão lu-
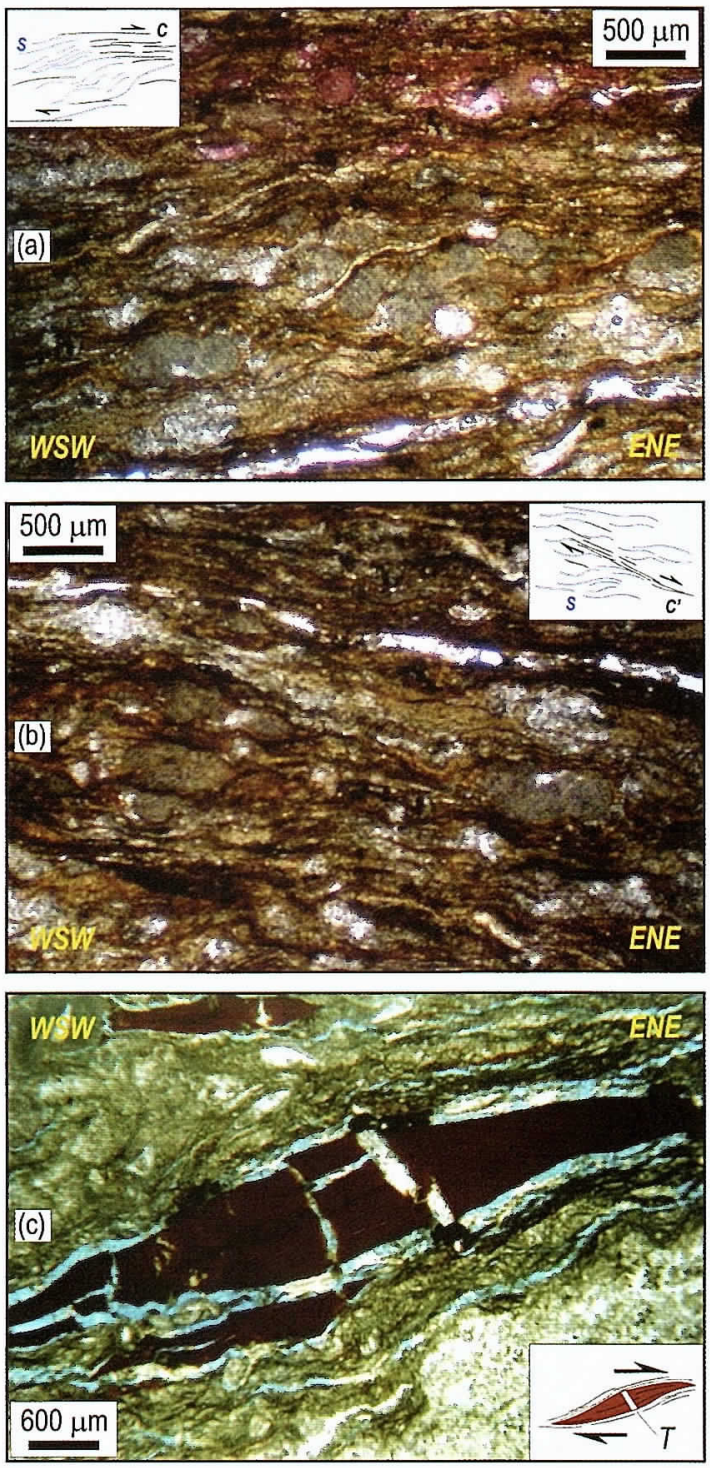

Figura 8 - Estruturas $S$-C-C' desenvolvidas durante a deformação $D_{l}$. (a) Trama obliqua $S$-C desenvolvida sobre a laminação de uma marga, indicativa de sentido de transporte tectônico para ENE. Nicóis paralelos. Poço $2 \mathrm{~V}$; (b) trama $S-C$ ' relacionada aos cisalhamentos $C_{1}$ e desenvolvida sobre a laminação de uma marga, com disposição indicativa de sentido de transporte de massa para ENE. Nicóis paralelos. Poço 2V; (c) fragmento de matéria orgânica em disposição sigmoidal relacionada às estruturas D, com assimetria que indica transporte tectônico para ENE. Nicóis paralelos. Poço 6V. Localização dos poços na figura 2.

gar às falhas normais que, por seu turno, são estruturas cujo aspecto varia de frágil/hidroplástico a estritamente frágil. Geralmente, os marcadores são os mesmos que os observados nas zonas de cisalhamento, como níveis internos à laminação/trama composta $\mathrm{S}_{0}+\mathrm{C}_{1}$ (Fig. 10b), veios de calcita (Fig. 10c) e fragmentos de matéria or- 

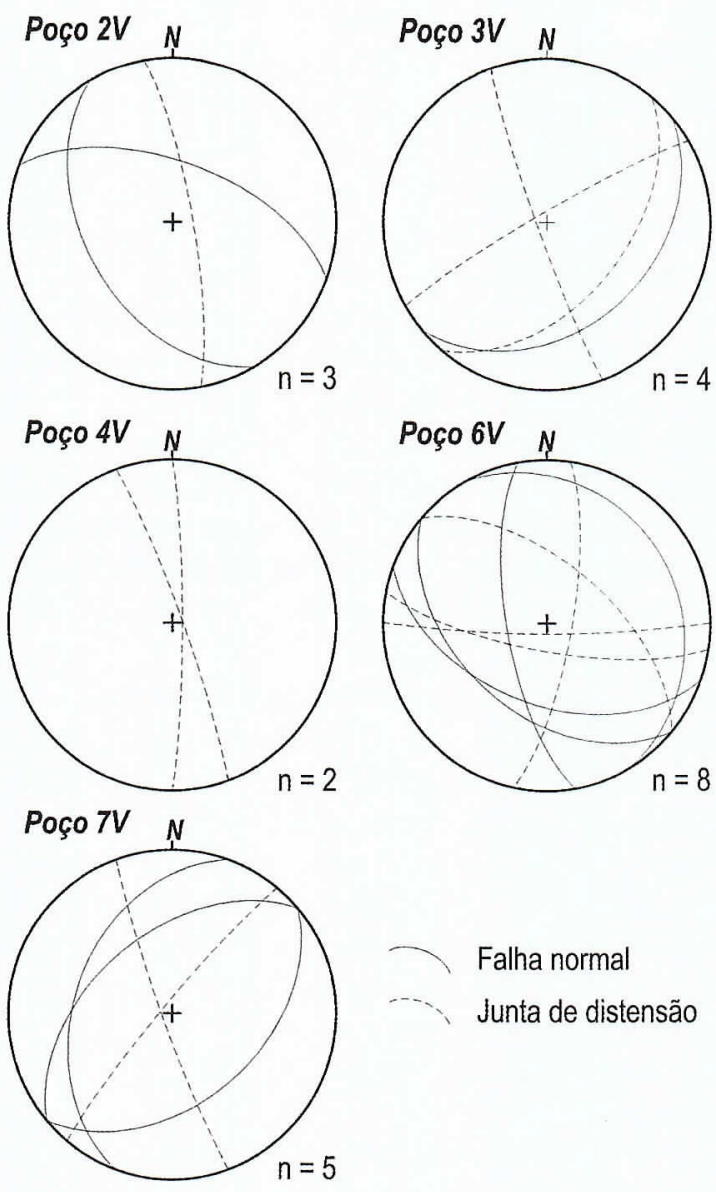

Falha normal

Junta de distensão

Figura 9 - Estereogramas de Schmidt (hemisfério inferior) para o subconjunto de estruturas frágeis relacionado à deformação $D$, afetando o Membro Trairí. Localização dos poços na figura 2.

gânica.

A maior parte dos critérios cinemáticos identificados nas estruturas $\mathrm{D}_{1}$ aponta um sentido de transporte tectônico principal que varia entre ENE e NE (Fig. 9). Entretanto, não foi raro encontrar, em um mesmo poço, indicadores que apontassem para sentidos opostos, para WSW ou SW (Fig. 9).

\section{REGISTRO DA DEFORMAÇÃO PÓS-LITIFICAÇÃO} $\mathrm{O}$ segundo conjunto de estruturas, $\mathrm{D}_{2}$, de caráter estritamente frágil, é caracterizado por falhas normais, geralmente de alto ângulo (Fig. 11a) e com orientações mais variadas (E-W, NE-SW e NNW-SSE - Fig. 12), que interceptam a laminação e, principalmente, as estruturas $\mathrm{D}_{1}$. As falhas normais $\mathrm{D}_{2}$ são diferenciadas das estruturas $\mathrm{D}_{1}$ principalmente pelo desenvolvimento de microtexturas cataclásticas, pela ausência de arrasto associado ao deslocamento, pela sua orientação e pelo tipo de preenchimento.

Espelhos-de-falha oblíquos a $\mathrm{S}_{0}$, com orientações similares às falhas normais ou paralelos à laminação, exibem películas de argilominerais recristalizados (Fig. 11b) contendo fibras (slickenlines). Estes espelhos
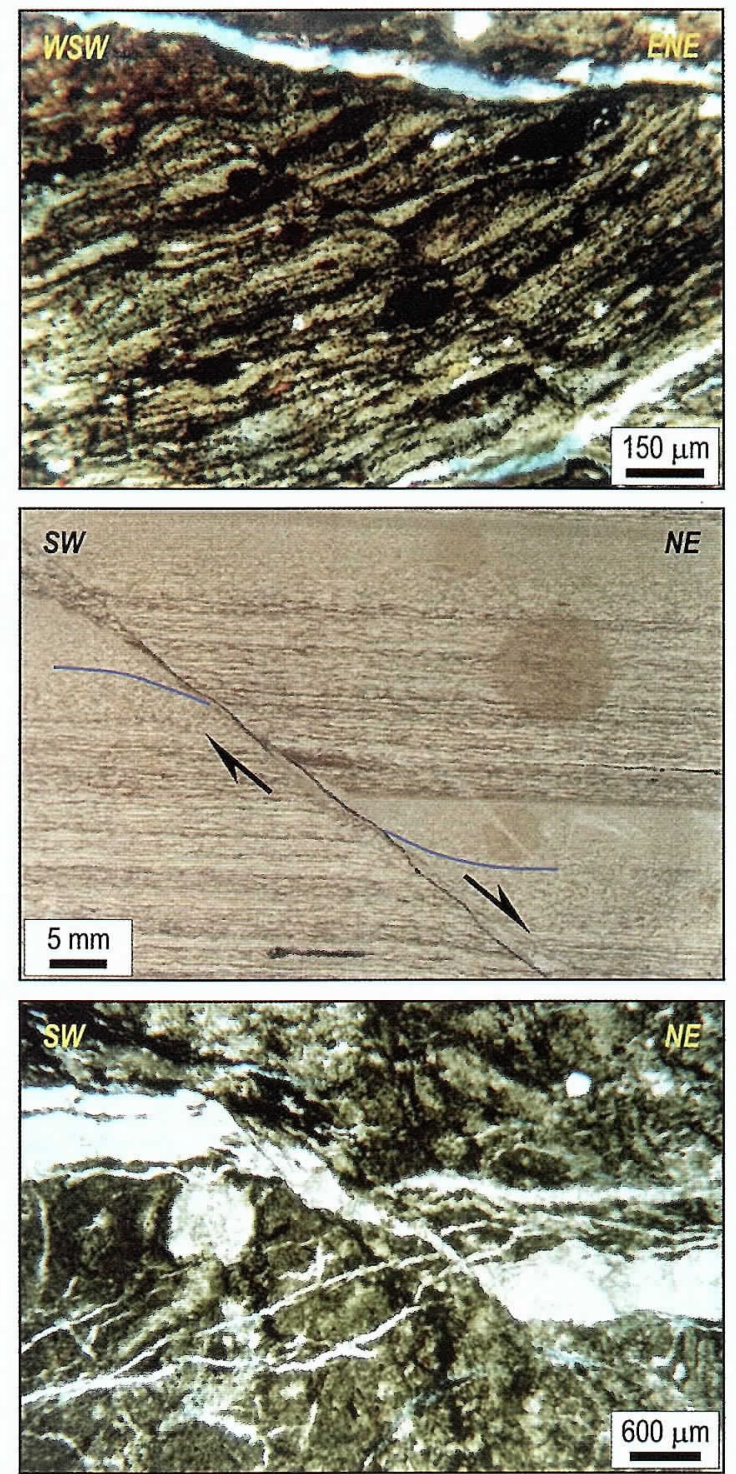

Figura 10 - Aspectos microestruturais das es-

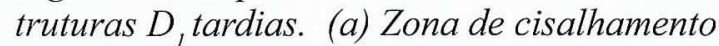
frágil/hidroplástica $N W-S E$, relacionada às estruturas $D_{l}$, desenvolvendo arrasto e rompimento da laminação de um folhelho. Nicóis paralelos. Poço $3 \mathrm{~V}$; (b) falha normal NW-SE, relacionada às estruturas $D$ mais tardias, afetando o acamamento de calcilutito laminado. Poço 6V; (c) veio de calcita suborizontal afetado por falhas escalonadas $D, N W-S E$. Nicóis paralelos. Poço 4V. Localização dos poços na figura 2.

são caracteristicamente encontrados em rochas com alto conteúdo de argilominerais, notadamente nos fothelhos, e são originados pela forte fricção das rochas, sob taxas de deformação muito elevadas.

Juntas distensionais também estão relacionadas às estruturas $\mathrm{D}_{2}$, compreendendo superfícies subverticais, de direção principal NW-SE. As juntas $\mathrm{D}_{2}$ aproveitam descontinuidades internas às fraturas mais antigas (como os contatos intercristalinos) para propa- 

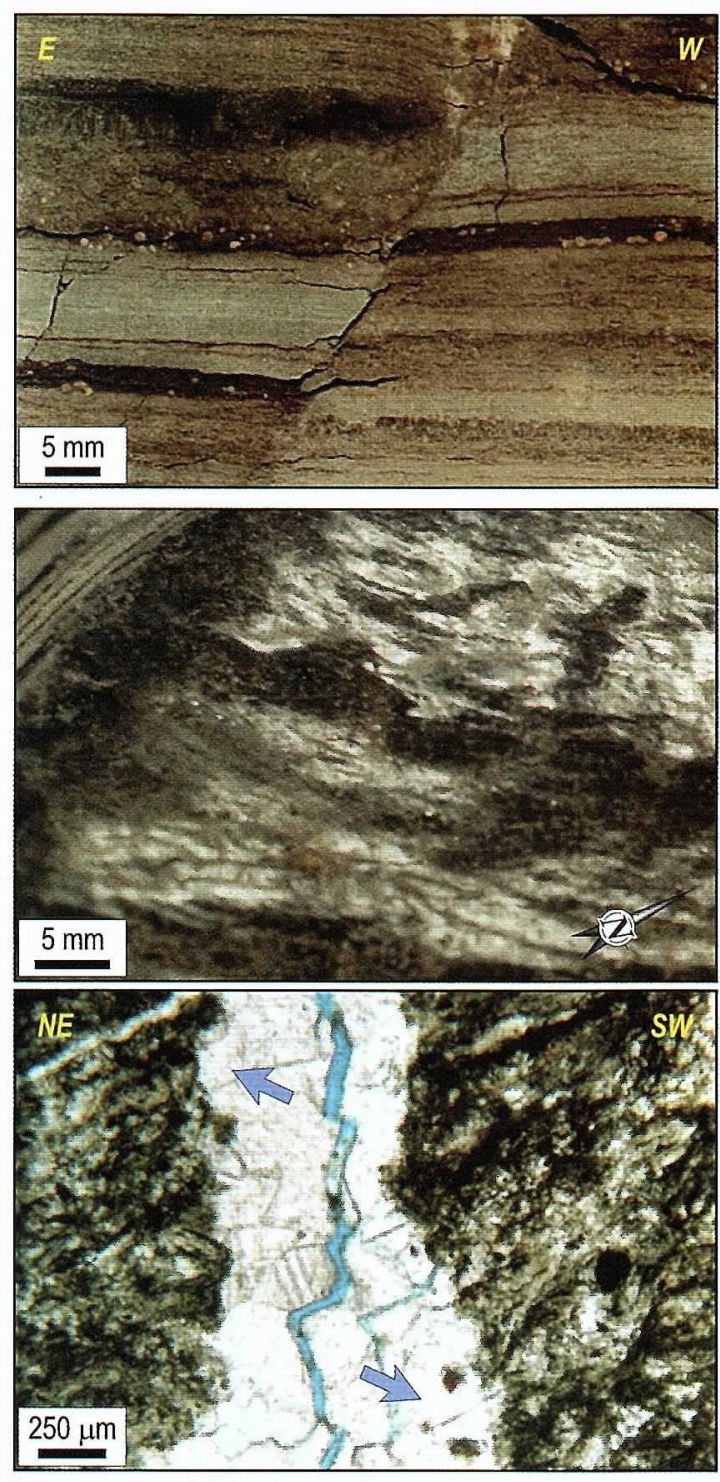

Figura 11 - Aspectos microestruturais das estruturas $D_{2}$. (a) Falha normal $D_{2}$ de direção $N$-S afetando calcilutito acamadado. Poço 4V; (b) plano de falhamento $D$, suborizontal, exibindo estrias de direção NE-SW, desenvolvidas sobre um espelho de falha formado por peliculas de argilominerais recristalizados. Poço $6 V$; (c) veio de calcita $D_{p}$, de direção $N W-S E$, reativado durante a deformação relacionada às estruturas $D_{2}$. Nicóis paralelos. Poço $4 \mathrm{~V}$. Localização dos poços na figura 2.

garem-se, normalmente apresentando uma componente de movimento oblíquo (Fig. 11c). São estruturas abertas, na maior parte das vezes secas ou, eventualmente, apresentando impregnação por óleo.

As estruturas $\mathrm{D}_{2}$ denotam uma idade mais jovem que as precedentes, tendo sido originadas sob condições estritamente frágeis, ou seja, tais estruturas desenvolveram-se quando as rochas da Formação Paracuru já estavam completamente litificadas.

\section{Análise de Perfis de Imagem}

DISTRIBUIÇÃOEDENSIDADEDASFRATURAS Os poços analisados $(8 \mathrm{H}, 9 \mathrm{H}$ e $10 \mathrm{H})$ navegam ao longo de um pacote principal de rochas carbonáticas, com intercalações de brechas, diamictitos e folhelhos. A análise dos perfis de imagem passou inicialmente pela divisão dos mesmos em segmentos estruturais.

A análise de distribuição de fraturas nos poços $8 \mathrm{H}, 9 \mathrm{H}$ e $10 \mathrm{H}$ foi realizada por meio da construção de gráficos que confrontam o número de fraturas observadas versus profundidade, aliados às suas respectivas curvas de número acumulado de fraturas observadas. A densidade de fraturas $\left(\rho_{f}\right)$ foi determinada pela razão entre o número de fraturas observadas em cada segmento estrutural dos perfis de imagem e o comprimento em metros do respectivo segmento.

No poço $8 \mathrm{H}$, as fraturas concentram-se em três intervalos principais (Fig. 13a), o que pode indicar a presença de falhas nas proximidades ou que foram interceptadas pelo poço. Dos três poços analisados, o $8 \mathrm{H}$ foi o que apresentou os valores mais elevados de $\rho_{\mathrm{f}}$, compreendendo valores médios em torno de 2,3 (fraturas por metro). Os segmentos I, V, VI e VII são os que apresentaram os maiores valores, superiores a 4,5 , chegando a atingir o valor excepcional de 9,2 no segmento VI. Por outro lado, os segmentos III e IV são muito pobres em fraturas.

No poço $9 \mathrm{H}$ a distribuição é bem mais esparsa, o que resulta em valores de $\rho_{\mathrm{f}}$ também muito baixos. $\mathrm{O}$ maior número de fraturas está concentrado no intervalo superior do poço, a partir de onde, a concentração cai notadamente e a distribuição é mais irregular (Fig. 13b). Excetuando o segmento I, no qual $\rho_{\mathrm{f}}$ atinge 2,5, todos os demais segmentos apresentam valores médios de $\rho_{\mathrm{f}}$ muito baixos.

No trecho perfilado do poço $10 \mathrm{H}$ ocorre um aumento progressivo do número de fraturas com a distância percorrida. As mudanças mais bruscas na inclinação da curva de freqüência acumulada são observadas entre os segmentos I e VI, onde o poço possui mergulhos relativamente mais elevados. Neste setor, o poço atravessa porções com pequenas quantidades de fraturas (trechos subverticais da curva de número acumulado - Fig. 13c), separados por trechos menores com aumento repentino no número de fraturas. A partir do segmento VII, o número de fraturas aumenta gradualmente, pelo fato de o poço encontrar-se horizontalizado e ter interceptado um número aproximadamente constante de fraturas.

Ao longo de sua trajetória, o poço $10 \mathrm{H}$ interceptou um total de 170 fraturas. A maior parte delas (165) é condutiva, ou seja, possibilitaram a infiltração do fluido empregado durante a perfilagem. As fraturas identificadas geralmente correspondem a estruturas bastante delgadas, com espessura milimétrica, excepcionalmente ultrapassando $10 \mathrm{~mm}$.

$\mathrm{O}$ trecho do perfil compreendido entre os segmentos estruturais I a V é caracterizado por $\rho_{\mathrm{f}}$ baixa, com valores entre 0,14 e 0,52 (média de 0,35 ). A passagem do segmento $\mathrm{V}$ para o VI é marcada por um acentuado aumento de $\rho_{\mathrm{f}}$, que oscila de 0,14 a 0,65 . 

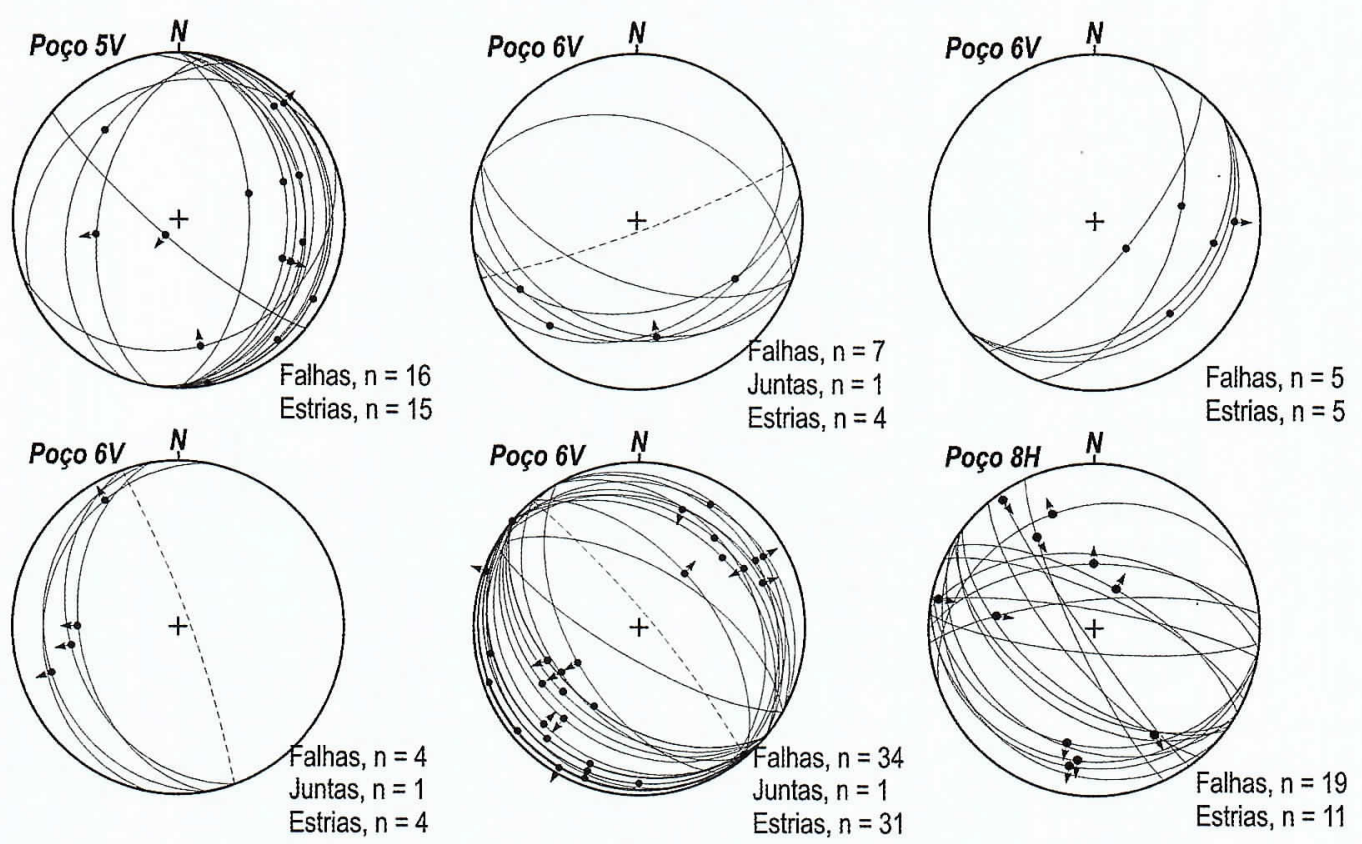

Falhas

. Juntas de distensão

Estrias

Figura 12 - Estereogramas de Schmidt (hemisfério inferior) para o conjunto de estruturas $\mathrm{D}_{2}$ afetando as rochas do Membro Trairí. Localização dos poços na figura 2.
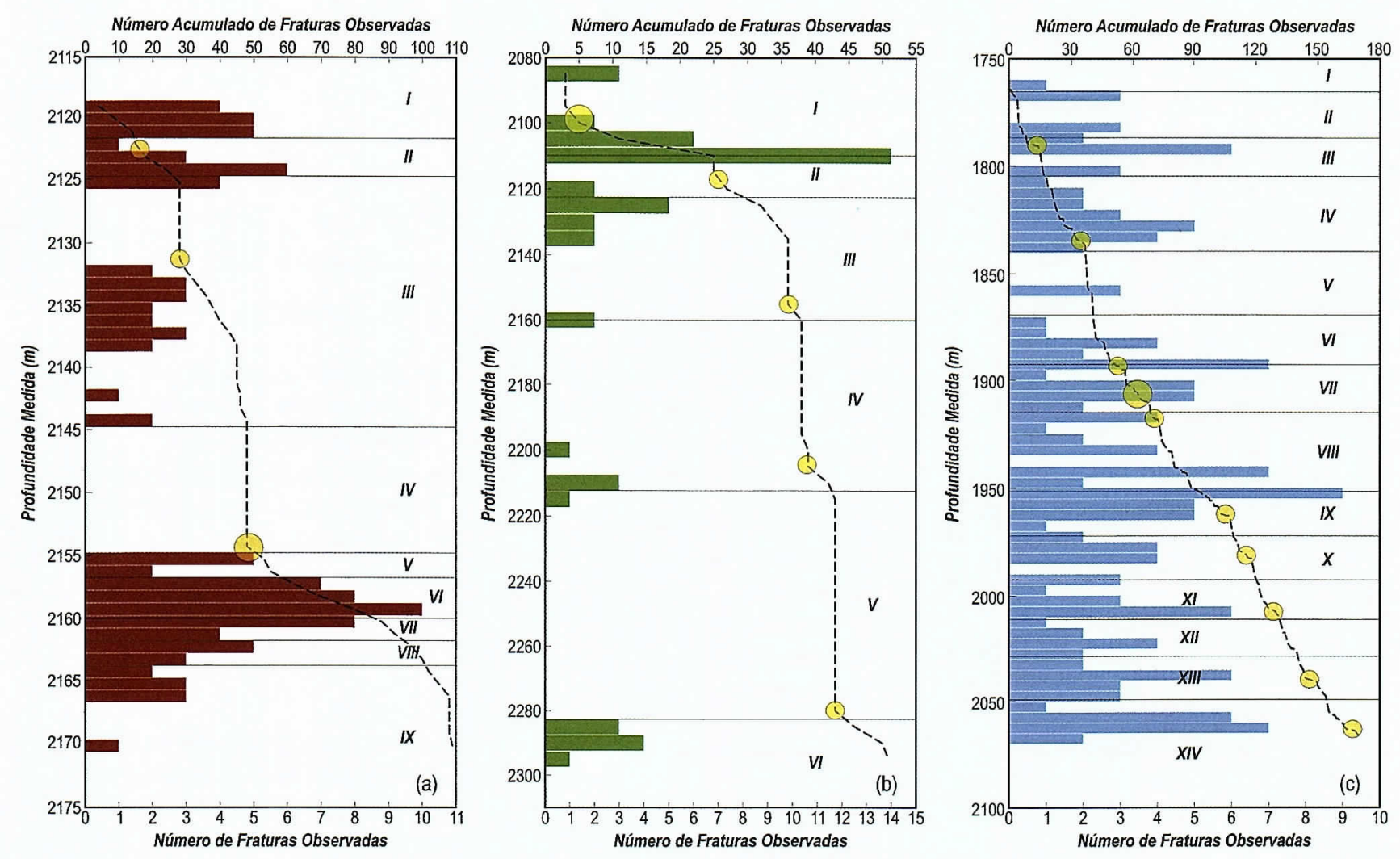

Figura 13 - Quantidade de fraturas observadas em função da profundidade medida, interpretadas dos perfis de imagem dos poços $8 \mathrm{H}$ (a), $9 \mathrm{H}$ (b) e $10 \mathrm{H}$ (c). As linhas tracejadas representam número acumulado de fraturas com a profundidade. Os círculos denotam regiões de maior concentração de fraturas. Localização dos poços na figura 2. 
Dos segmentos VII a XIII, os valores de $\rho_{\mathrm{f}}$ permanecem compreendidos entre 0,53 e 0,73 (média de 0,63 ), caindo bruscamente para 0,2 no segmento XIV. Estas oscilações podem refletir tanto (i) anisotropias naturais na distribuição (e na orientação) das fraturas interceptadas, como (ii) amostragem seletiva das mesmas graças a mudanças na direção e na inclinação do poço.

ESPAÇAMENTO ENTRE AS FRATURAS A análise de espaçamento entre as fraturas nos poços foi baseada em diagramas de número de fraturas observadas versus espaçamento (que distingue populações de fraturas com espaçamentos similares e definem o espaçamento predominante) e número acumulado de fraturas observadas versus espaçamento, bilogarítmico (que permite a identificação de padrões de distribuição das fraturas).

A maioria das fraturas identificadas no poço $8 \mathrm{H}$ está espaçada a menos de 1 metro (Fig. 14a). Em detalhe, ao analisar-se somente as fraturas com espaçamento igual ou inferior a 1 metro (Fig. 14b), pode ser observado que cerca de $40 \%$ estão espaçadas entre 5 e $15 \mathrm{~cm}$ umas das outras. A distribuição dos dados no diagrama bilogarítmico (Fig. 14c) denota uma linha reta de coeficiente angular igual a $-0,88$, ou seja, o espaçamento obedece a uma distribuição fractal.

No poço $9 \mathrm{H}$ o espaçamento entre a maior parte das fraturas é inferior a 5 metros (Fig. 15a). No conjunto de fraturas com espaçamento inferior a 1 metro, cerca de $65 \%$ dos planos de fraturamento estão espaçados entre 20 e $30 \mathrm{~cm}$ (Fig. 15b). A distribuição das fraturas segundo seu espaçamento também se alinha, grosso modo, conforme uma reta de coeficiente angular igual a $-0,53$ (Fig. 15c), caracterizando, assim, uma distribuição fractal.

De modo diferente dos poços anteriores, que são essencialmente horizontais, o poço $10 \mathrm{H}$ apresenta um trecho inicial inclinado, compreendendo os segmentos estruturais I a VI, seguido de um trecho horizontal, que inclui os segmentos VII a XIV. Levando em consideração toda a extensão do poço, a maioria das fraturas interpretadas apresenta espaçamento inferior a 2 metros (Fig. 16a). Deve ser destacado que a quantidade de fraturas no poço decresce de modo aproximadamente exponencial em função do espaçamento. Para o trecho inclinado, um comportamento similar é apresentado pelas fraturas encontradas, cuja maioria está espaçada de menos de 1 metro de distância (Fig. 16b). No trecho horizontal do poço $10 \mathrm{H}$, a maior parte das fraturas apresenta espaçamento menor ou igual a $1,5 \mathrm{~m}$ (Fig. 16c). Quando o trecho horizontal é analisado em mais detalhe, considerando apenas o conjunto de fraturas com espaçamento inferior a 1 metro (Fig. 16d), é observado que a maioria delas está espaçada a distâncias compreendidas entre 5 e $30 \mathrm{~cm}$. Um segundo conjunto, subordinado, apresenta espaçamento da ordem de 55 a $65 \mathrm{~cm}$.

Para o perfil de imagem do poço $10 \mathrm{H}$, os dados de fraturamento dispõem-se segundo uma curva com concavidade voltada para a origem dos eixos (Fig. 16e), o que indica a presença de uma distribuição exponen-
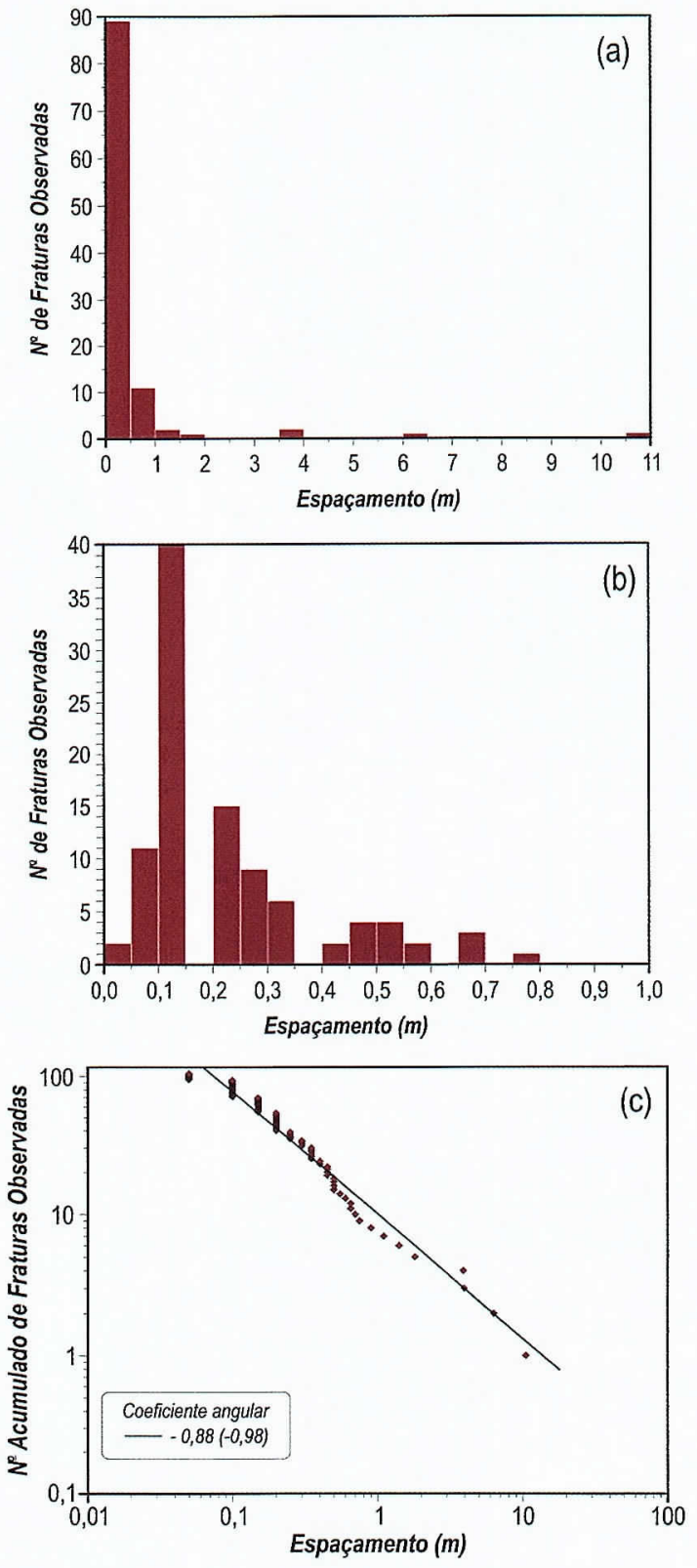

Figura 14 - Espaçamento entre as fraturas para o poço 8 H. Histograma confrontando o espaçamento e o número de fraturas observadas para todos os dados do poço (a) e somente para fraturas com espaçamento inferior a 1 metro (b). Em (c) é confrontado o espaçamento e o número acumulado de fraturas observadas. Localização do poço na figura 2.

cial. No entanto, é possível ser observado também que a curva como um todo pode ser subdividida em três trechos menores, dois dos quais se comportam de maneira retilínea (dispostas entre os intervalos de 0,05 e $0,8 \mathrm{~m}$, e 0,6 e $3 \mathrm{~m}$ ), e cada qual possuindo inclinações distintas, com coeficientes angulares iguais a $-3,30$ e $-1,38$, como mostrado pelo traçado das retas de regressão linear. Neste tipo de arranjo é possível observar, então, que as fraturas interceptadas ao longo do poço podem ser subdivididas em populações que obedecem a uma 
distribuição fractal. Distribuições similares são observadas para os trechos inclinado e horizontal separadamente (Figs. 16f,g). Para ambos os casos, é observado que os dados também se alinham segundo uma curva, denotando, pois, uma distribuição exponencial, mas que pode ser subdividida em trechos retos menores. As particularidades residem nas inclinações dos segmentos de reta originados: para o trecho inclinado (Fig. 16f) os segmentos possuem coeficientes angulares iguais a $-2,84$ e $-1,54$, enquanto que para o trecho horizontal (Fig. 16g) as inclinações são de $-3,15$ e $-0,74$.

ORIENTAÇÃO DAS FRATURAS De uma maneira geral, no poço $8 \mathrm{H}$, as fraturas são de alto ângulo e exibem direção principal N-S a NE-SW, apresentando mergulhos que variam principalmente de moderados a elevados $\left(50^{\circ}\right.$ a $\left.90^{\circ}\right)$. Fraturas com mergulho suave ocorrem essencialmente entre os segmentos IV e IX.

Para o poço $9 \mathrm{H}$, as fraturas orientam-se de modo um pouco mais irregular, com segmentos apresentando um baixo número de fraturas, como o segmento I, ou mesmo sem fraturas, a exemplo do segmento V. Entre II e IV ocorrem, sobretudo, fraturas de direção NNESSW, notadamente no segmento II. Vale ressaltar ainda que, no segmento IV, ocorrem algumas fraturas de direção WNW-ESE. Nos segmentos VI e VII as fraturas apresentam mergulhos mais suaves e direção ENEWSW (VI) ou WNW-ESE (VII).

No poço $10 \mathrm{H}$, do segmento I ao VI, as fraturas distribuem-se de modo bastante variado, estando subdivididas entre várias populações de direções NNE-SSW, N-S, NNW-SSE, ENE-WSW (principal) e WNW-ESE (Fig. 17). A partir do segmento VII as fraturas passam a assumir direções mais constantes: de NNE-SSW a NNW-SSE (com alguns máximos com direção ENEWSW) entre os segmentos VII e X, culminando em NW-SE (com oscilações para NNW-SSE) a partir do segmento XI (Fig. 17). Os mergulhos dos planos de fraturamento variam de suaves a elevados (Fig. 17), particularmente no segmento VIII, que exibe uma alta concentração de fraturas.

As variações na orientação das fraturas podem ser explicadas quer por uma distribuição anisotrópica natural, quer por uma amostragem seletiva promovida pelo poço $10 \mathrm{H}$. Não por coincidência, o próprio poço também mostra direção variável: dos segmentos I a VI ele possui direção NW-SE a WNW-ESE; direção aproximadamente E-W nos segmentos VII; ENE-WSW nos segmentos VIII e IX; e, finalmente, NE-SW do segmento $\mathrm{X}$ ao XIV. Isto demonstra que há uma tendência do poço perfurado interceptar preferencialmente aquelas fraturas que se dispõem em ângulos elevados com sua direção. Além disso, é possível considerar que existam pelo menos dois conjuntos principais de fraturas com direções distintas que foram atravessados pelo poço (Fig. 17): enquanto o trecho WNW-ESE do poço interceptou, sobretudo, aquelas fraturas de direção NNESSW a ENE-WSW, o segmento ENE-WSW amostrou principalmente as estruturas orientadas aproximadamente segundo NNW-SSE/NW-SE.
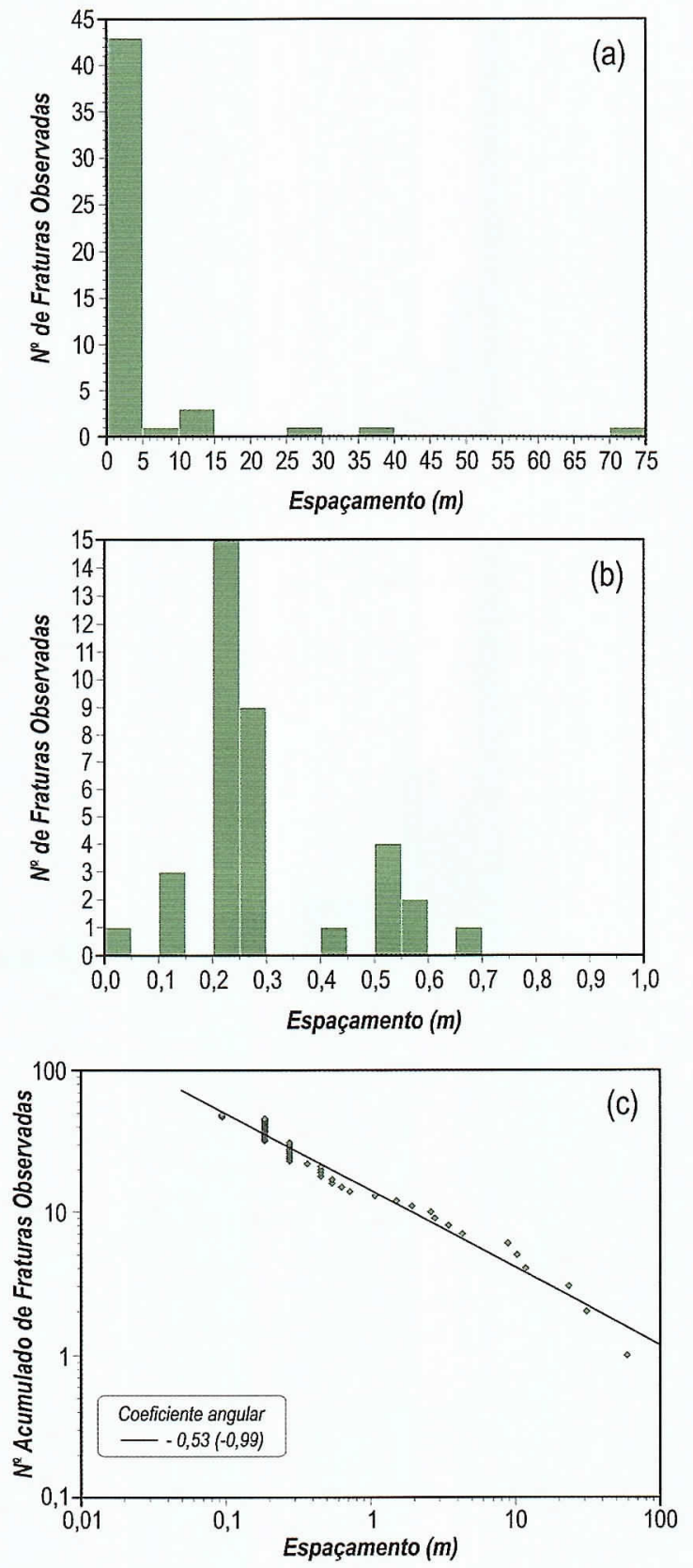

Figura 15 - Espaçamento entre as fraturas para o poço $9 \mathrm{H}$. Histograma confrontando o espaçamento e o número de fraturas observadas para todos os dados do poço (a) e somente para fraturas com espaçamento inferior a 1 metro (b). Em (c) é confrontado o espaçamento e o número acumulado de fraturas observadas. Localização do poço na figura 2.

SÍNTESE DOS RESULTADOS OBTIDOS COMA ANÁLISE DOS PERFIS DE IMAGEM A partir da análise dos perfis de imagem dos três poços horizontais estudados, é possível realizar uma interpretação integrada, de modo a confrontar as diferenças e comparar as similaridades entre cada um deles.

A densidade de fraturas interpretadas varia en- 

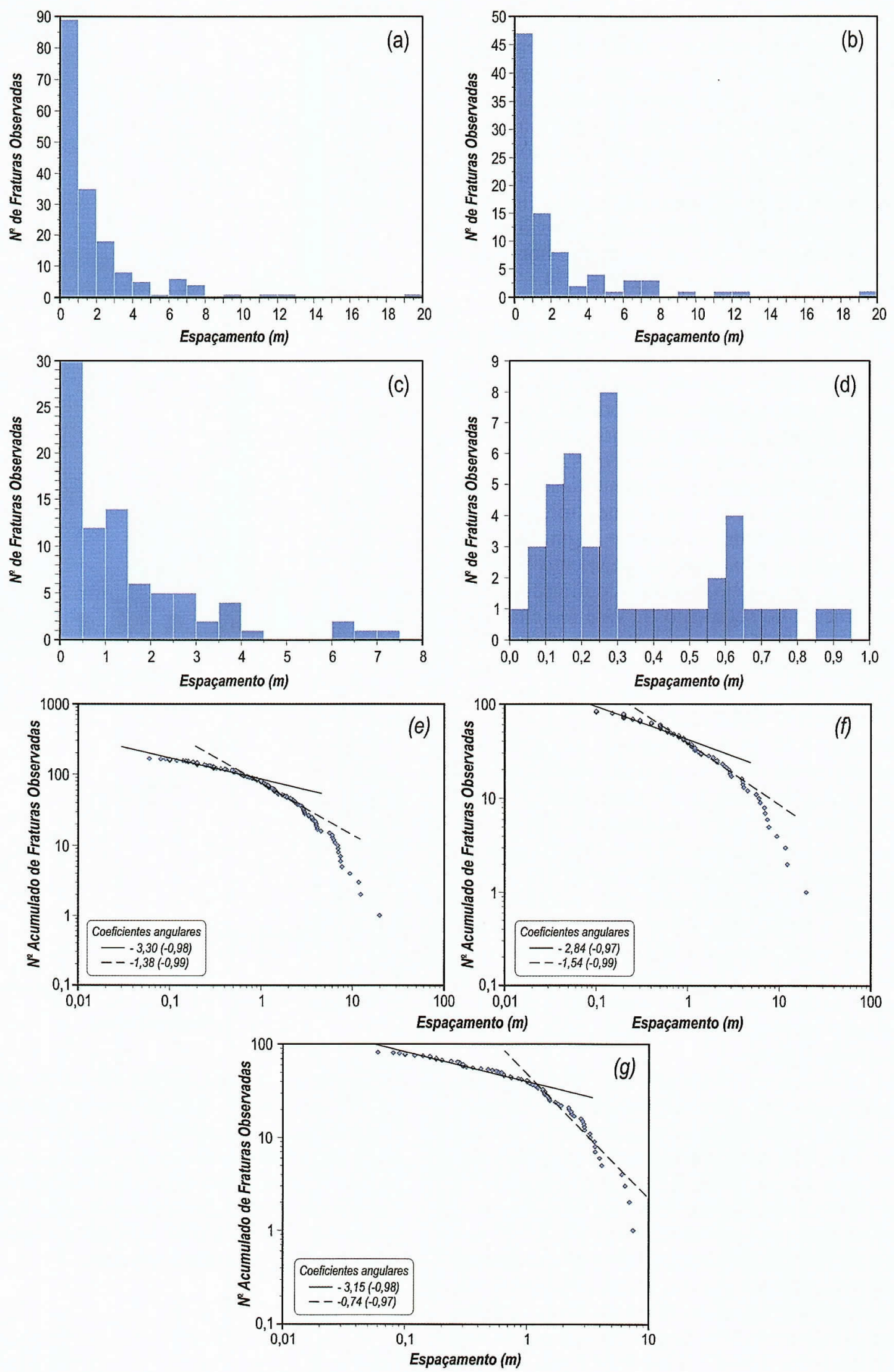

Figura 16 - Relações entre o espaçamento e a distribuição de fraturas no poço 10H. Diagramas de número de fraturas versus espaçamento: (a) todos os dados do poço; (b) dados do trecho inclinado; (c) dados do trecho horizontal; (d) dados apenas para as fraturas com espaçamento igual ou menor que um metro no trecho horizontal. Diagramas bilogarítmicos de número acumulado de fraturas versus espaçamento: (e) todos os dados do poço; ( $f$ ) dados do trecho inclinado; (g) dados do trecho horizontal. Localização do poço na figura 2. 


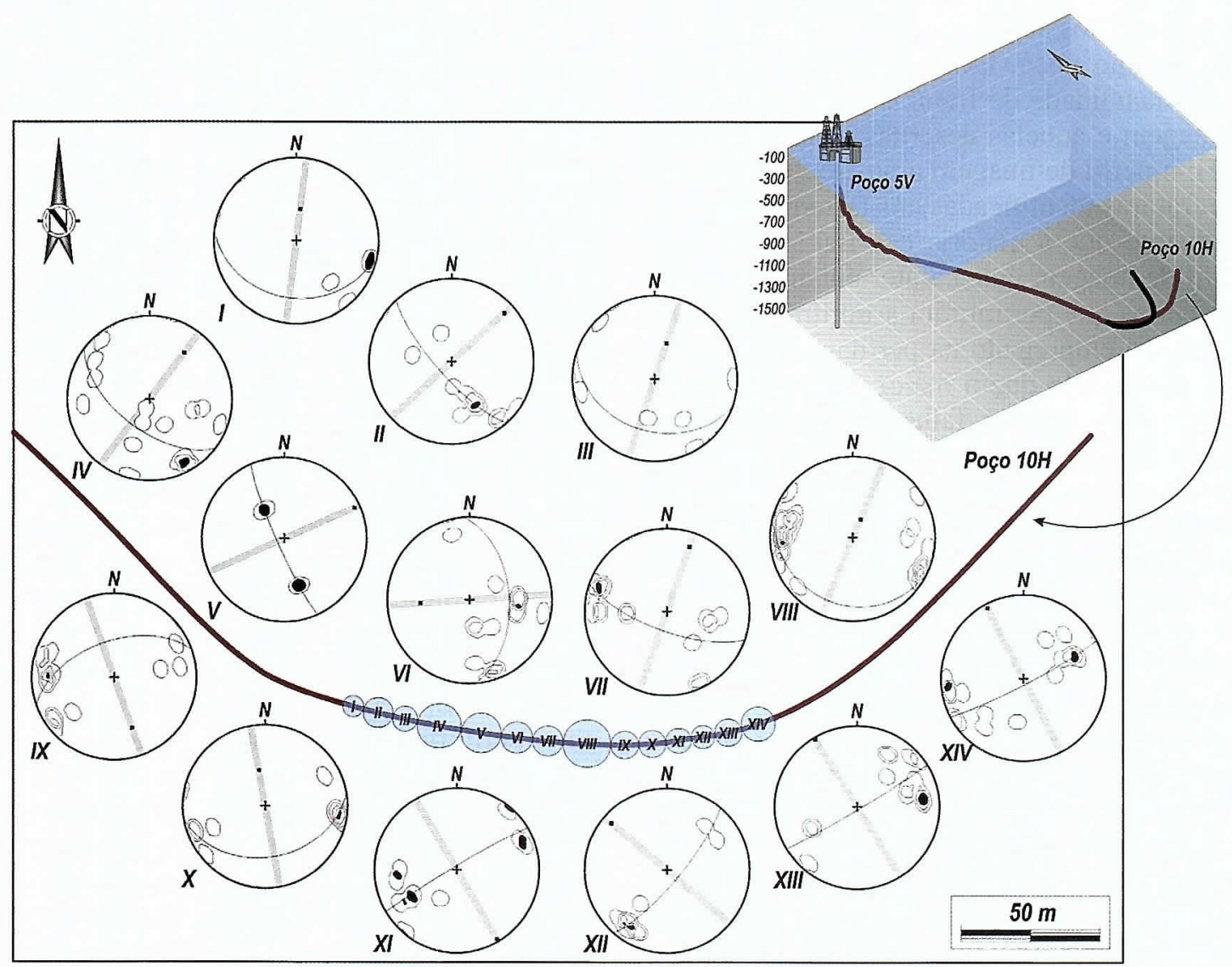

Figura 17 - Trajetória do poço $10 \mathrm{H}$ e a divisão em segmentos estruturais. Para os segmentos I a XIV são mostrados os respectivos estereogramas de Schmidt (hemisfério inferior) com o contorno ( $1 \%$ de área) para os pólos das fraturas interpretadas por meio do perfil de imagem. As barras em cinza indicam a direção média das fraturas determinada a partir das guirlandas. Os pontos em preto correspondem aos pólos das guirlandas. Localização do poço na figura 2.

tre cada um dos poços, sendo notadamente maior no poço $8 \mathrm{H}$ do que nos demais. A diferença de densidade pode ter relação com a localização dos poços no Campo de Xaréu, assim como pode ser um reflexo de sua orientação em relação ao falhamento.

Os poços $8 \mathrm{H}$ e $9 \mathrm{H}$ foram perfurados na região noroeste do Campo de Xaréu. A orientação do poço 8H é essencialmente NW-SE, enquanto que o poço $9 \mathrm{H}$, perfurado nas proximidades do anterior, possui direção oscilando entre NNW-SSE e NNE-SSW. Já o poço $10 \mathrm{H}$, que foi perfurado na região central do campo, possui orientação variável ao longo de sua trajetória, iniciando com WNW-ESE, passando por E-W e ENE-WSW e culminando com NE-SW. Com base na premissa de que as linhas de varredura (que, no caso, são os poços estudados) amostrarão, preferencialmente, aquelas fraturas dispostas em maior ângulo com relação a sua direção, duas conclusões podem ser tiradas: (i) a quantidade de fraturas interceptadas pode ter sido influenciada pela localização dos poços no campo. Os poços $8 \mathrm{H}$ e $9 \mathrm{H}$ poderiam estar localizados em uma região mais estruturada do campo, apresentando uma maior quantidade de falhas, principalmente subsísmicas; e (ii) a orientação do poço também deve ter influenciado na densidade de fraturas atravessadas e detectadas pela perfilagem, uma vez que, a despeito de estarem localizados na mesma região, os poços $8 \mathrm{H}$ e $9 \mathrm{H}$ apresentam diferenças significativas na densidade de fraturas.

Perfurações com direção NW-SE (como o poço $8 \mathrm{H}$ ) provavelmente interceptam melhor as fraturas, ao menos na porção do Campo de Xaréu em que o poço $8 \mathrm{H}$ está localizado. Neste caso, as fraturas amostradas teriam, preferencialmente, direção NE-SW. Por outro lado, poços com orientação aproximada N-S (a exemplo do $9 \mathrm{H}$ ) interceptariam principalmente fraturas de direção $\mathrm{E}-\mathrm{W}$ que, no caso em lide, praticamente não são conhecidas dos dados de poços. O poço $10 \mathrm{H}$ estaria localizado em uma região naturalmente com baixa concentração de fraturas, uma vez que, embora a orientação do poço varie, não foram observados aumentos relevantes na densidade destas estruturas, sobretudo quando comparados com os altos valores de densidade de fraturas $\left(\rho_{\mathrm{f}}\right)$ apresentados pelo poço $8 \mathrm{H}$.

Particularmente no caso do poço $8 \mathrm{H}$, em que um trecho foi tanto perfilado como testemunhado, é possível comparar os resultados obtidos por ambos os métodos. Inicialmente pode ser observado que os três testemunhos do poço $8 \mathrm{H}$ foram amostrados no interva- 
lo correspondente aos segmentos IV a VI do perfil de imagem do mesmo poço. Existe uma importante discrepância na quantidade de fraturas interpretadas pelo perfil de imagem e aquelas descritas nos testemunhos do poço 8H: o perfil de imagem amostrou mais do que o dobro de fraturas identificadas nos testemunhos.

Enquanto que a maioria das fraturas observadas no perfil de imagem é de caráter condutivo, isto é, estruturas abertas que permitiram a infiltração do fluido de perfuração empregado na perfilagem, nos testemunhos foi constatado que a maior parte das fraturas corresponde, na verdade, a falhas normais (algumas poucas falhas inversas) com uma espessura muito pouco expressiva ou, geralmente, apresentando-se fechadas. Tal observação leva a certa incongruência entre os dois métodos de obtenção de dados de fraturamento no poço 8H: o método direto (testemunhos) amostrou uma quantidade consideravelmente menor de fraturas que o indireto (FMI). Uma explicação poderia residir na diferença de área amostrada, pois o diâmetro perfilado pode ser quase duas vezes maior que o testemunhado. Sendo assim, é possível que, ao nível do diâmetro do poço testemunhado, muitas das fraturas (das que estão presentes no perfil de imagem) não tenham sido interceptadas. Esta hipótese explicaria a interceptação de uma quantidade menor de fraturas, mas não o fato de que nos testemunhos foram identificadas muito poucas fraturas abertas, que teriam um comportamento condutivo. Neste caso pode ser levantada a tese de que o perfil de imagem identificou "eventos" que de fato não se tratam de fraturas que, todavia, foram interpretados como tal após o processamento dos dados. Qualquer que seja a explicação deve ser ressaltado que, embora seja uma ferramenta poderosa, os perfis de imagem não devem ser encarados como uma panacéia, pois, como qualquer método indireto de obtenção de dados, artefatos podem estar presentes, prejudicando a interpretação dos resultados obtidos.

DISCUSSÕES O arcabouço estrutural do Campo de Xaréu é tipificado por um arranjo principal de falhas normais/oblíquas, com perfil lístrico ou em rampa-patamar-rampa. Observando os pacotes sedimentares que estas estruturas afetam, é possível caracterizar que as falhas apresentaram pelo menos três fases de atividade principais (o que pode incluir etapas de recorrência). A primeira fase de ativação das falhas alude-se à própria origem do Campo de Xaréu e da Sub-Bacia de Mundaú, no Eoaptiano. Esta fase de deformação frágil é caracterizada pelas falhas que afetam a sequiência "rifte" da sub-bacia, a Formação Mundaú, e/ou o "embasamento". As falhas apresentaram atividade concomitante à deposição da Formação Mundaú, como denotado pelo espessamento de seção sedimentar observada nesta unidade. O segundo pulso tectônico ocorreu, pelo menos, logo em seguida à deposição da Formação Paracuru. Finalmente, a última etapa de ativação/reativação ocorreu após a deposição dos estratos basais do Membro Uruburetama, da Formação Ubarana, uma vez que estes se encontram afetados por falhas.
A caracterização estrutural em meso e microescalas possibilitou o reconhecimento de uma série de estruturas (fraturamentos) presentes no Campo de Xaréu, originados durante (pelo menos) duas fases de deformação principais. A caracterização estrutural completa destes fraturamentos, o que envolve estilo, cinemática, orientação e idade, pode servir de subsídio para a definição de atributos similares para as principais falhas que estruturam o campo, sobretudo quanto à sua cinemática e, conseqüentemente, sentido de transporte tectônico predominante. A partir dos perfis de imagem, porém, esta caracterização pode ser feita apenas de modo parcial, devido às limitações intrínsecas à própria perfilagem: neste tipo de ferramenta é muito difícil ou mesmo impossível definir estilo, idade e tipo de preenchimento das fraturas, atributos que são cruciais para a caracterização estrutural. Assim, a comparação entre os dados de testemunhos e de perfis de imagem somente pode ser feita de maneira tentativa. Exceção deve ser feita ao poço $8 \mathrm{H}$, pois, este é o único que possui testemunhos e um perfil de imagem, ambos obtidos em um mesmo trecho do poço. Ainda assim, como a escala de amostragem de ambas as ferramentas é bastante diferente, a segurança das correlações fica prejudicada.

De uma maneira geral, os perfis de imagem demonstraram que as fraturas no Campo de Xaréu possuem direções principais NE-SW, N-S e NW-SE. Nos testemunhos, a maior parte das fraturas abertas identificadas pertence ao conjunto de estruturas $\mathrm{D}_{2}$, cuja idade é atribuída ao Neógeno (em parte por indicarem deformação pós-litificação); estas fraturas possuem direções principais N-S e NW-SE, ou seja, são similares à dos perfis de imagem, mas, em vários casos, apresentam mergulhos mais suaves. A maior quantidade de fraturas $\mathrm{D}_{2}$ de mergulho baixo nos testemunhos pode ser atribuída à amostragem seletiva, de vez que os poços testemunhados são estritamente verticais. Os poços perfilados (que são suborizontais) interceptaram, sobretudo, fraturas subverticais. Deste modo, é possível que a maior parte das fraturas identificadas nos perfis de imagem corresponda às estruturas $\mathrm{D}_{2}$ dos testemunhos, embora a limitação imposta pela perfilagem impossibilite a extração de interpretações mais detalhadas.

Como a maior parte das fraturas interpretadas nos perfis de imagem corresponde a fraturas condutivas e, nos testemunhos, são as estruturas $D_{2}$ que apresentam estas características (juntas distensionais abertas, localmente impregnadas por óleo), a correlação tornase mais segura. Juntas distensionais relacionadas às estruturas $D_{1}$ estão caracteristicamente preenchidas por veios de calcita. Neste caso, os veios apareceriam nos perfis de imagem como fraturas não-condutivas, que são de número consideravelmente mais reduzido.

CONCLUSÕES O Campo de Xaréu é recortado por um arranjo de falhas normais de direção NW-SE e que mergulham principalmente para NE. As falhas constituem um leque lístrico distensional e estão enraizadas ao longo de uma superfície de detachment, apresentando atividade tectônica durante várias etapas da evolução 
do campo. A deformação relacionada às falhas normais, sobretudo às falhas de Mundaú e de Xaréu, desenvolveu um dobramento do tipo anticlinal rollover nas camadas do bloco do teto, afetando as formações Mundaú e Paracuru. Sinclinais de borda são estruturas que ocorrem de forma local, na porção sudoeste do campo.

Por intermédio da análise de testemunhos, foram reconhecidas duas gerações de estruturas em escala meso a microscópica. O conjunto mais precoce, $\mathrm{D}_{1}$, é formado principalmente por estruturas de caráter hidroplástico, representadas por cisalhamentos paralelos ao acamamento das rochas do Membro Trairí que evoluem para estruturas com caráter frágil. Ambos os conjuntos de estruturas denotam sentido de transporte tectônico para ENE. Uma vez que parte das estruturas $\mathrm{D}_{1}$ apresenta características sin a tardilitificação (caráter hidroplástico), o seu desenvolvimento deve ter ocorrido ainda no Aptiano. Falhas normais com orientações variadas, espelhos de falhas contendo argilominerais recristalizados e juntas distensionais impregnadas por óleo representam as estruturas $\mathrm{D}_{2}$, cuja idade inferida é reportada ao Neógeno.

Nos três poços analisados a partir dos perfis de imagem, as fraturas distribuem-se em enxames, provavelmente devido à associação com falhas. Os poços $9 \mathrm{H}$ e $10 \mathrm{H}$ possuem uma baixa concentração de fraturas, enquanto que poço $8 \mathrm{H}$ apresenta densidade média de fraturas relativamente alta. A densidade das fraturas nos poços apresenta relação direta com o espaçamento, de vez que no poço $8 \mathrm{H}$, a maior parte das fraturas está distanciada a menos de $15 \mathrm{~cm}$ umas das outras, enquanto que nos poços $9 \mathrm{H}$ e $10 \mathrm{H}$, a maioria das estruturas somente apresenta espaçamento inferior a $30 \mathrm{~cm}$. Em todos os poços, as fraturas são dominantemente de mergulho elevado. No poço $8 \mathrm{H}$ elas apresentam direção principal entre N-S e NNE-SSW, enquanto que no poço $9 \mathrm{H}$ as fraturas apresentam direções bastante variadas. No poço $10 \mathrm{H}$, por seu turno, existe uma razoável relação entre a direção do poço, que varia de WNW-ESE até ENE-WSW, e a orientação das fraturas, de modo que o poço intercepta preferencialmente aquelas estruturas dispostas em maior ângulo com a sua direção de perfuração.

Agradecimentos Os autores gostariam de agradecer à PETROBRAS UN-RNCE pela cessão dos dados utilizados. Ao projeto "Caracterização Geomecânica de Reservatórios Heterogêneos para Aumento do Fator de Recuperação através da Perfuração de Poços Multilaterais (FINEP/CT-PETRO/PETROBRAS)" pelo financiamento das pesquisas. À Paradigm Geophysical Company pela cessão das licenças acadêmicas do programa de interpretação sísmica (SeisX).

\section{Referências}

Antunes A. F. 2004. Evolução tectono-estrutural do Campo de Xaréu (Sub-Bacia de Mundaú, Bacia do Ceará-NE do Brasil): Abordagem Multiescala e Pluriferramental. Tese de Doutorado, Centro de Ciências Exatas e da Terra, Universidade Federal do Rio Grande do Norte, 372p.

Antunes A.F., Jardim de Sá E.F., Souza A.A.S., Keller Filho O., Lima Neto F.F., Moraes A., Alves da Silva F.C., Medeiros W.E. 2001. Caracterização estrutural de um reservatório carbonático na Bacia do Ceará, Nordeste do Brasil. In: SBQ, Congr. Bras. P\&D Petróleo \& Gás, 1, Anais, p.374.

Antunes A.F., Jardim de Sá E.F., Matos R.M.D., Alves da Silva F.C., Souza A.A.S., Keller Filho O., Lima Neto F.F., Moraes A. 2002. Structural characterization of the Trairí Carbonate Reservoir in the Xaréu Oil Field (Ceará Basin, Northeast Brazil). In: AAPG, Annual Meeting, $C D-R O M$.

Antunes A.F., Jardim de Sá E.F., Matos R.M.D., Souza A.A.S., Lima Neto F.F., Moraes A., Keller Filho O., Carvalho Costa P.R., Alves da Silva F.C., Medeiros W.E. 2003. O Campo de Xaréu (Bacia do Ceará - Nordeste do Brasil): caracterização estrutural através de uma abordagem multi-escala. In: SBG/Núcleo Rio de Janeiro, Simp. Nac. Est. Tect., 9, Atas, p.412-414.

Beltrami C.V., Alves L.E.M., Feijó F.J. 1994. Bacia do Ceará. Bol. Geoc. PETROBRAS, 8(1):117-125.

Costa I.G., Beltrami C.V., Alves L.E.M. 1989. A evolução tectono-sedimentar e o hábitat do óleo da Bacia do Ceará. In: PETROBRAS/DepEx, Sem. Interp. Explor., 1, Anais, 75-85.
Davison I. 1998. Tectonic and hydrocarbon distribution along the Brazilian South Atlantic margin. In: Cameron N.R., Bate R.H. \& Clure V.S. (eds.) Oil and gas habitats of the South Atlantic. Special Publication of the Geological Society of London 153, CD-ROM.

Farias P.R.C., Alves A.C., Silva J.G.F., Souza Filho L.V. 1998. Litofaciamento de testemunhos do Calcário, Trairí, Campo de Xaréu, Sub-Bacia de Mundaú. Natal, PETROBRAS, Relatório Interno, 71p.

Matos R.M.D. 2000. Tectonic evolution of the Equatorial South Atlantic. In: Mohriak W. \& Talwani M. (eds.) Atlantic rifts and continental margins. Geophysical Monograph 115, American Geophysical Union, p. 331-353.

Matos R.M.D., Waick R.N., Pimentel V.P.C. 1996. Bacia do Ceará (Mundaú): uma fase rifte convencional!? In: SBG/ Núcleo Bahia-Sergipe, Congr. Bras. Geol., 39, Anais, 5:358-362.

PETROBRAS. 1996. Arcabouço estrutural das bacias Potiguar e Ceará integrado ao mapa geológico simplificado do Estado do Ceará, escala 1:500.000. Natal, PETROBRAS, 1 mapa geológico, escala 1:500.000.

Ribeiro R.J.L, Horschutz P.M.C., Beer R., Carvalho M.D., Plavnik B., Machado L.R.L., Martins J.A.S., Lima L.C., Santos J.A.C.M., Azevedo M.A.S. 1986. Aumento de produtividade do Calcário Trairí. Rio de Janeiro, PETROBRAS, Relatório Interno, 76p.

Manuscrito BR 06

Submetido em 19 de dezembro de 2007 Aceito em 21 de março de 2008 